\title{
Structures and mechanical properties of Ti-Nb-Cr-V-Ni-Al refractory high entropy alloys
}

\author{
E.S. Panina ${ }^{a}$, N.Yu Yurchenko ${ }^{a}$, S.V. Zherebtsov ${ }^{a}$, M.A. Tikhonovsky ${ }^{b}$, M.V. Mishunin ${ }^{a}$, N. \\ D. Stepanov ${ }^{\mathrm{a}, "}$
}

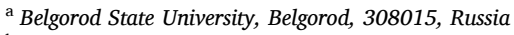

b National Science Center "Kharkiv Institute of Physics and Technology" NAS of Ukraine, Kharkiv, 61108, Ukraine

\section{A R T I C L E I N F O}

\section{Keywords:}

Refractory high entropy alloys

Alloy design

Microstructure

Sigma phase

Mechanical properties

\begin{abstract}
A B S T R A C T
Four refractory high entropy alloys with different chemical compositions, which can be calculated as $\mathrm{Ti}_{(50}$ $1.5625 \mathrm{x}) \mathrm{Nb}_{(30-0.9375 \mathrm{x})} \mathrm{Cr}_{10} \mathrm{~V}_{10} \mathrm{Ni}_{1.5 \mathrm{x}} \mathrm{Al}_{\mathrm{x}}(\mathrm{x}=0,5,7,10)$, were prepared by arc melting to determine the effect of $\mathrm{Ni}$ and $\mathrm{Al}$ on the phase composition, structure and mechanical properties. Each alloy was studied in both the as-cast and annealed at $1000{ }^{\circ} \mathrm{C}$ for $24 \mathrm{~h}$ conditions; compression tests at room temperature or at $800{ }^{\circ} \mathrm{C}$ was used to examine mechanical behavior of the alloys and the effect of deformation on microstructure. The replacement of $\mathrm{Ti}$ and $\mathrm{Nb}$ with $\mathrm{Al}$ and $\mathrm{Ni}$ resulted in the formation of the $\mathrm{Ti}$, Ni-rich $\sigma$-phase and $\mathrm{Ti}_{2} \mathrm{Ni}$ phases in the bcc matrix in contrast to the ThermoCalc predictions which suggests the formation of the bcc solid solution, B2, and Laves phases. The Ti, Ni-rich $\sigma$-phase can't also be expected from the analysis of the corresponding binary and ternary phase diagrams. Annealing did not result in noticeable changes in the microstructure. The formation of the $\sigma$ and $\mathrm{Ti}_{2} \mathrm{Ni}$ phases resulted in a considerable increase in strength (from 745 to $1600 \mathrm{MPa}$ ) and decrease in ductility (from a thickness reduction $\geq 50 \%$ to fracture in the elastic region) at room temperature. An increase in the testing temperature to $800{ }^{\circ} \mathrm{C}$ resulted in softening to and a substantial increase in ductility of all the alloys. Complex relationships between the fraction of the second phases and mechanical properties were discussed.
\end{abstract}

\section{Introduction}

The so-called refractory high entropy alloys (RHEAs) were introduced recently as a new class of metallic alloys potentially suitable for high-temperature applications $[1,2]$. Widely used Ni-based superalloys cannot satisfy future needs for high-temperature materials, for example, in the aerospace sector, due to the limited incipient melting temperature [3]. RHEAs and related refractory complex concentrated alloys (RCCAs) are multi-component (generally the number of components is $\geq 5$ ) close to equiatomic alloys composed of elements with high melting temperatures like $\mathrm{Cr}, \mathrm{Hf}, \mathrm{Mo}, \mathrm{Nb}, \mathrm{Ta}, \mathrm{Ti}, \mathrm{V}, \mathrm{W}$ and $\mathrm{Zr}$; the presence of non-refractory elements like $\mathrm{Al}, \mathrm{Co}, \mathrm{Ni}$, and $\mathrm{Si}$ is also possible [2,4]. RHEAs and RCCAs with impressive strength at temperatures up to $1600^{\circ} \mathrm{C}$ and promising oxidation resistance have already been reported [2,5-18]. However, further optimization of composition, structure, and properties of such alloys is still required to develop materials attractive for practical applications.

Mechanical properties of the metallic alloys are primarily dependent on their structure and phase composition. RHEAs mainly consist of a random base centered cubic (bcc) solid solution and a B2 ordered phase, also based on the bcc lattice [2]. The B2 phase is often observed in alloys with $\mathrm{Al}$ [19-23]. Some alloys were revealed to have a single B2 phase structure [20,23,24], sometimes containing a small amount of non-coherent secondary phases like a Laves phase, $\sigma$-phase or $\mathrm{Zr}$ aluminides $[25,26]$.

However the most attractive option is probably associated with the production of a mixture of the bcc $+\mathrm{B} 2$ coherent phases. In some alloys cuboidal or plate-like bcc precipitates were found in a continuous B2 matrix; this type of microstructure was sometimes referred to as a "superalloy"-like structure [21,22] and these alloys can be termed as "refractory high entropy superalloys" (RHESAs) [22]. Some of the RHESAs has already demonstrated high specific strength at $\mathrm{T} \leq 1200{ }^{\circ} \mathrm{C}$, significantly outperforming properties of conventional Ni-based superalloys [1,22]. However, RHESAs generally possess limited ductility at low temperatures, mostly due to the ordered nature of the matrix phase. Some efforts to "invert" the structure of the available RHESAs into the

\footnotetext{
* Corresponding author. Laboratory of Bulk Nanostructured Materials, Belgorod State University, Pobeda 85, Belgorod, 803015, Russia.

E-mail addresses: stepanov@bsu.edu.ru, stepanov.nikita@icloud.com (N.D. Stepanov).
} 
bcc matrix with B2 precipitates by proper alloying and/or heat treatment [27], did not clarify thoroughly the accessibility of this goal.

Nevertheless, the idea to obtain a better combination of mechanical properties through the formation of coherent precipitates in the bcc solid solution remains very promising. In high entropy alloys based on transition metals (TMHEAs) the formation of coherent particles in a stable solid solution matrix can be attained through the addition of the proper alloying elements [28-38].

To extend this approach to RHEAs, a $\mathrm{Ti}_{50} \mathrm{Nb}_{30} \mathrm{Cr}_{10} \mathrm{~V}_{10}$ alloy with a single bcc solid solution phase structure developed earlier $[39,40]$ was used as the reference point. The $\mathrm{Ti}_{50} \mathrm{Nb}_{30} \mathrm{Cr}_{10} \mathrm{~V}_{10}$ alloy was then doped with $\mathrm{Ni}$ and $\mathrm{Al}$ (the contents of $\mathrm{Ti}$ and $\mathrm{Nb}$ were proportionally decreased). The following reasons were taken in consideration: (i) binary $\mathrm{NiAl}$ has the $\mathrm{B} 2$ structure presumably coherent with the bcc matrix; (ii) the enthalpy of the intermetallic phase formation in the Ni-Al pair is much more negative in comparison with any other possible pair ( $(\mathrm{Ti}, \mathrm{Nb}$, $\mathrm{Cr}, \mathrm{V})-\mathrm{Al}$ ) [41]; i.e. the formation of $\mathrm{NiAl}$ is most preferable among all other Al-containing phases. A preliminary assessment of the phase composition of proposed alloys by the CALPHAD method (see Fig. 1) suggested also the formation in some of them the B2 particles in the bcc matrix. Different amounts of $\mathrm{Ni}$ and $\mathrm{Al}$ will presumably produce different fractions of second phase particles in the bcc matrix.

To determine the effect of $\mathrm{Ni}$ and $\mathrm{Al}$ experimentally, a set of alloys with different chemical compositions (which can be calculated as $\mathrm{Ti}_{(50-}$ ${ }_{1.5625 \mathrm{x})} \mathrm{Nb}_{(30-0.9375 \mathrm{x})} \mathrm{Cr}_{10} \mathrm{~V}_{10} \mathrm{Ni}_{1.5 \mathrm{x}} \mathrm{Al}_{\mathrm{x}}(\mathrm{x}=0,5,7,10)$ ) was prepared by arc melting. Structure and compression mechanical properties of the alloys at room and elevated $\left(800^{\circ} \mathrm{C}\right)$ temperatures were investigated.

\section{Materials and methods}

The $\mathrm{Ti}_{50} \mathrm{Nb}_{30} \mathrm{Cr}_{10} \mathrm{~V}_{10}$ (referred hereafter to as $\mathrm{x}=0$ ), $\mathrm{Ti}_{42.2} \mathrm{Nb}_{25.3} \mathrm{Cr}_{10} \mathrm{~V}_{10} \mathrm{Ni}_{7.5} \mathrm{Al}_{5}(\mathrm{x}=5), \mathrm{Ti}_{39.1} \mathrm{Nb}_{23.4} \mathrm{Cr}_{10} \mathrm{~V}_{10} \mathrm{Ni}_{10.5} \mathrm{Al}_{7}(\mathrm{x}=7)$ and $\mathrm{Ti}_{34.4} \mathrm{Nb}_{20.6} \mathrm{Cr}_{10} \mathrm{~V}_{10} \mathrm{Ni}_{15} \mathrm{Al}_{10}(\mathrm{x}=10)$ alloys were produced by arc melting of the elements in a low-pressure, high-purity argon atmosphere inside a water-cooled copper cavity. The ingots were remelted at least 5 times to ensure chemical homogeneity; the alloying elements purity was no less than $99.9 \mathrm{wt} \%$.

The produced ingots of the alloys had dimensions of about $6 \times 12 \times$ $40 \mathrm{~mm}^{3}$. Specimens measured $4 \times 4 \times 6 \mathrm{~mm}^{3}$ were cut from the ingots using an electric discharge machine. Some of the specimens were annealed at $1000{ }^{\circ} \mathrm{C}$ for $24 \mathrm{~h}$. Prior to annealing, the specimens were sealed in vacuumed $\left(10^{-2}\right.$ Torr) quartz tubes filled with titanium chips to prevent oxidation.

The microstructure of the alloys in the as-cast and annealed at 1000

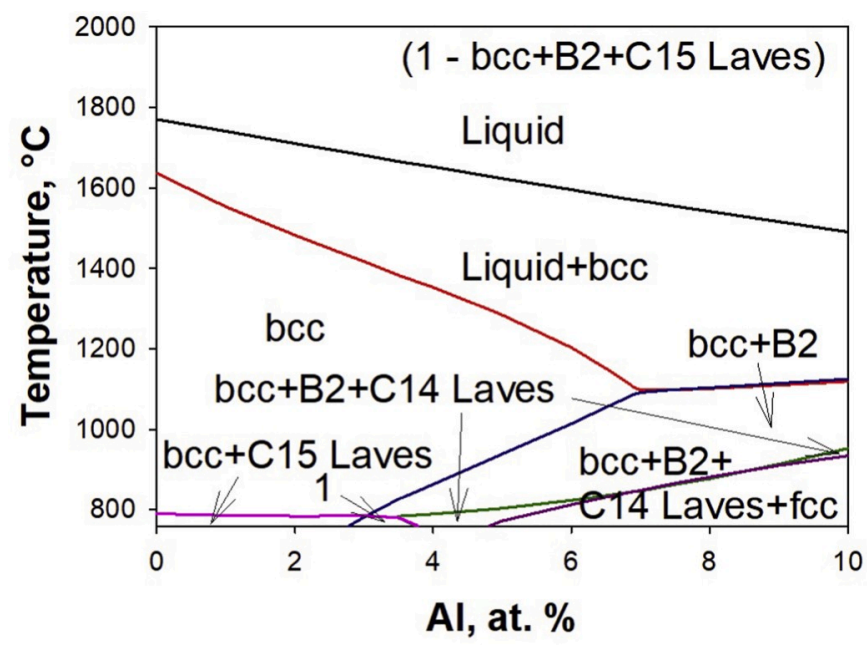

Fig. 1. Equilibrium phases in the $\mathrm{Ti}_{(50-1.5625 \mathrm{x})} \mathrm{Nb}_{(30-0.9375 \mathrm{x})} \mathrm{Cr}_{10} \mathrm{~V}_{10} \mathrm{Ni}_{1.5 \mathrm{x}} \mathrm{Al}_{\mathrm{x}}$ alloys as a function of temperature and $\mathrm{Al}$ concentration $(\mathrm{x})$.
${ }^{\circ} \mathrm{C}$ conditions were studied using X-ray diffraction (XRD), scanning electron microscopy (SEM) and electron backscatter diffraction (EBSD) analysis. Specimens for XRD, SEM, and EBSD were produced by careful mechanical polishing. XRD analysis was performed using a RIGAKU diffractometer with $\mathrm{CuK} \alpha$ radiation. SEM investigations were performed on an FEI Quanta 600 field emission gun (FEG) microscope equipped with an energy-dispersive (EDS) detector. EBSD was conducted using an FEI Nova NanoSEM 450 FEG SEM equipped with a Hikari EBSD detector and a TSL OIM ${ }^{\mathrm{TM}}$ system version 6.0. This software was used to generate inverse pole figures (IPF) and phase maps. On the presented IPF maps the high angle boundaries (HABs) are indicated with black lines while white lines denote the low angle boundaries (LABs). The bcc, $\sigma$, and $\mathrm{Ti}_{2} \mathrm{Ni}$ phases are shown in the presented phase maps with red, green, and blue colors, respectively. All the EBSD maps are shown in the asobtained conditions without any additional cleanup procedures. The volume fractions of different phases were measured by the areal analysis of SEM-BSE images using a Digimizer Image Analysis Software and EBSD phase maps. The difference between the fractions of the phases measured from SEM-BSE and EBSD data for the same alloy and condition was $<2 \%$; the average value is given.

Nanohardness was measured using a Shimadzu DUH-211s Dynamic Ultra Micro Hardness Tester with a Berkovich tip. At least twenty indents were performed on each phase avoiding any influence from other phases. The maximum load of $50 \mathrm{mN}$ was applied for $5 \mathrm{~s}$; a loading speed was $6.662 \mathrm{mN} / \mathrm{s}$. The hardness was calculated using the Oliver and Pharr method [42].

Isothermal compression of the as-cast and annealed at $1000{ }^{\circ} \mathrm{C}$ rectangular specimens measured $4 \times 4 \times 6 \mathrm{~mm}^{3}$ was carried out at 22 or $800{ }^{\circ} \mathrm{C}$ using an Instron 300LX testing machine equipped with a radial furnace. The specimens were placed into the preheated to the testing temperature furnace and held for $\sim 10 \mathrm{~min}$ to equilibrate the temperature prior to testing. The temperature was controlled by a thermocouple attached to a side surface of the specimen. The initial strain rate was $10^{-4}$ $\mathrm{s}^{-1}$.

The equilibrium phase diagram was constructed using a Thermo-Calc (version 2019b) software and a TCHEA3 (high-entropy alloys) database.

\section{Results}

\subsection{Phase diagram}

Fig. 1 shows equilibrium phases in the $\mathrm{Ti}_{(50-1.5625 \mathrm{x})} \mathrm{Nb}_{(30-}$ $0.9375 \mathrm{x}) \mathrm{Cr}_{10} \mathrm{~V}_{10} \mathrm{Ni}_{1.5 \mathrm{x}} \mathrm{Al}_{\mathrm{x}}$ alloys as a function of temperature and $\mathrm{Al}$ concentration $(\mathrm{x})$. Phases stable at $1000^{\circ} \mathrm{C}$, their chemical composition and fractions in the alloys with $\mathrm{x}=0,5,7$ or 10 are given in Table 1 . One can clearly see that the phase composition of the alloys strongly depended on the $\mathrm{Al}$ concentration. The "base" $\mathrm{Ti}_{50} \mathrm{Nb}_{30} \mathrm{Cr}_{10} \mathrm{~V}_{10}$ alloy was solidified in a temperature interval of $1637-1770^{\circ} \mathrm{C}$ with the formation of a bcc solid solution upon solidification. Only the bcc phase remained stable during cooling till $790^{\circ} \mathrm{C}$. At $790^{\circ} \mathrm{C}$, a Cr, Nb-rich C15 (fcc) Laves phase precipitated.

The addition of $\mathrm{Al}$ (accompanied also by an increase in the Ni content at the expense of $\mathrm{Ti}$ and $\mathrm{Nb}$ ) had the following effects:

Table 1

Stable phases and their chemical compositions at $1000{ }^{\circ} \mathrm{C}$ in the $\mathrm{Ti}_{(50}$ ${ }_{1.5625 \mathrm{x})} \mathrm{Nb}_{(30-0.9375 \mathrm{x})} \mathrm{Cr}_{10} \mathrm{~V}_{10} \mathrm{Ni}_{1.5 \mathrm{x}} \mathrm{Al}_{\mathrm{x}}(\mathrm{x}=0,5,7,10)$ alloy according to the Thermo-Calc software.

\begin{tabular}{lllllllll}
\hline Alloy & $\begin{array}{l}\text { Stable } \\
\text { phases }\end{array}$ & $\mathrm{Ti}$ & $\mathrm{Nb}$ & $\mathrm{Cr}$ & $\mathrm{V}$ & $\mathrm{Ni}$ & $\mathrm{Al}$ & $\mathrm{V}_{\mathrm{f}}(\%)$ \\
\hline $\mathrm{x}=0$ & BCC & 48.8 & 31.2 & 10.0 & 10.0 & - & - & 100.0 \\
$\mathrm{x}=5$ & BCC & 42.5 & 25.0 & 10.0 & 10.0 & 7.5 & 5.0 & 100.0 \\
$\mathrm{x}=7$ & BCC & 40.0 & 23.0 & 10.2 & 10.2 & 9.0 & 7.6 & 96 \\
& B2 & 40.2 & 10.2 & 4.5 & 6.8 & 32.5 & 5.8 & 4 \\
$\mathrm{x}=10$ & BCC & 34.3 & 23.8 & 12.0 & 11.3 & 8.3 & 10.3 & 72 \\
& B2 & 36.7 & 10.8 & 5.2 & 6.8 & 31.1 & 9.4 & 28 \\
\hline
\end{tabular}


(i) A pronounced decrease in both the liquidus and solidus temperatures and some broadening of the solidification range. For example, the liquidus temperature monotonically decreased from $1770{ }^{\circ} \mathrm{C}$ to $1490{ }^{\circ} \mathrm{C}$ with an increase in $\mathrm{x}$ from 0 to 10 . The solidus temperature, meanwhile, first decreased from $1637^{\circ} \mathrm{C}$ to $1098^{\circ} \mathrm{C}$ with an increase in $\mathrm{x}$ from 0 to 7 , and then increased slightly to $1119^{\circ} \mathrm{C}$ at $\mathrm{x}=10$

(ii) A Ni-rich B2 phase started to appear at $\mathrm{x}=2.7$. Its solvus temperature increased quickly with an increase in the Al concentration. The B2 solvus temperature approached $1099^{\circ} \mathrm{C}$ and became slightly higher than the solidus temperature of the alloy.

(iii) The C15 (fcc) Laves phase transformed into a C14 (hexagonal) one at $\mathrm{x}=3.5-3.8$. Note that a similar $\mathrm{C} 15$ to $\mathrm{C} 14$ transformation was already demonstrated experimentally in some Al-Cr-Nb-Ti-V$\mathrm{Zr}$ RHEAs with an increase in the content of $\mathrm{Al}$ [15]. The C14 Laves phase was enriched with $\mathrm{Cr}$ and $\mathrm{Nb}$, the solvus temperature of this phase increased from $790^{\circ} \mathrm{C}$ to $953^{\circ} \mathrm{C}$ with an increase in $\mathrm{x}$ from 4 to 10 .

(iv) Finally, a Ni, Ti-rich fcc phase appeared at $\mathrm{x}=4.8$; the solvus temperature of this phase increased quickly approaching $953^{\circ} \mathrm{C}$ at $\mathrm{x}=10$.

\subsection{Structure of the as-cast alloy}

The effect of $\mathrm{Al}$ and $\mathrm{Ni}$ content on the structure of the program Ti-Nb$\mathrm{Cr}-\mathrm{V}-\mathrm{Ni}$-Al alloys in the as-cast condition was estimated by XRD (Fig. 2). The "starting" $\mathrm{Ti}_{50} \mathrm{Nb}_{30} \mathrm{Cr}_{10} \mathrm{~V}_{10}$ alloy had the single bcc phase structure with the lattice parameter of $0.3222 \mathrm{~nm}$ (lattice parameters of constitutive phases are given in Supplementary information, Table S1). The effect of $\mathrm{Ni}$ and $\mathrm{Al}$ was associated with the appearance of additional phases, namely a cubic $\mathrm{Ti}_{2} \mathrm{Ni}$ phase (the space group 227) and a tetragonal $\sigma$-phase (the space group 136). The lattice constant of the bcc phase reduced slightly to $0.3175-0.3179 \mathrm{~nm}$ when the content of $\mathrm{Ni}$ and $\mathrm{Al}$ increased. Some increase in the intensity of the $\sigma$-phase peaks and a decrease in the intensity of peaks from the bcc phase at high $\mathrm{Al} / \mathrm{Ni}$ concentrations should be noted.

The addition of $\mathrm{Al}$ (and $\mathrm{Ni}$ ) had a significant effect on the as-cast microstructure of the Ti-Nb-Cr-V-Ni-Al alloys (Fig. 3). The $\mathrm{Ti}_{50} \mathrm{Nb}_{30} \mathrm{Cr}_{10} \mathrm{~V}_{10}$ alloy had a single bcc phase structure, as confirmed by EBSD results (Fig. 3b). The average bcc grain size was $140 \pm 100 \mu \mathrm{m}$; however both quite fine $(\sim 50 \mu \mathrm{m})$ and very coarse $(\sim 500 \mu \mathrm{m})$ grains were found. Dendritic segregations were observed inside the bcc grains (Fig. 3a). Lighter dendritic areas (\#1 in Fig. 3a) were enriched with $\mathrm{Nb}$,

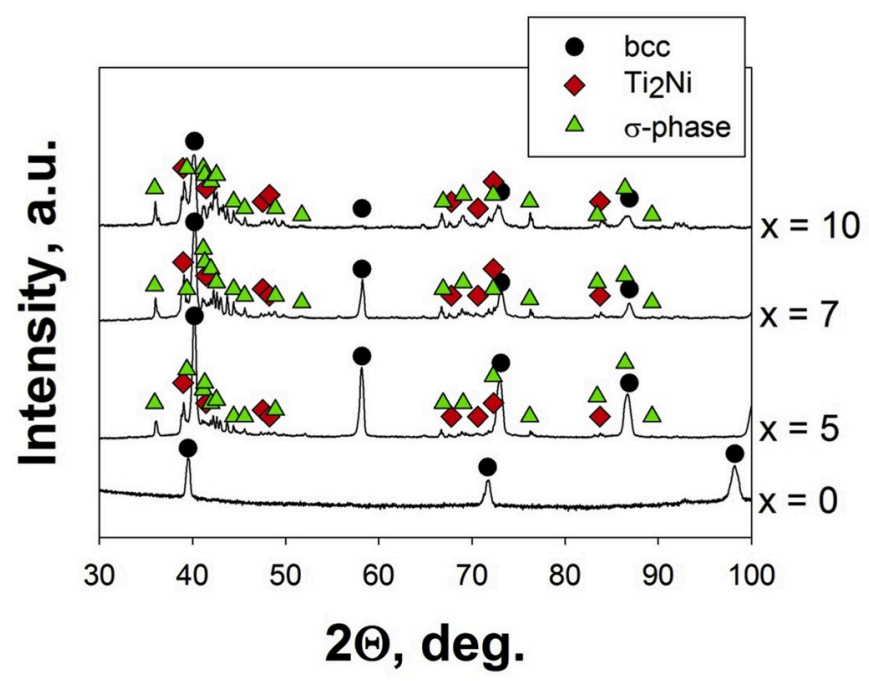

Fig. 2. XRD pattern of the Ti-Nb-Cr-V-Ni-Al alloys with different $\mathrm{Al}$ contents (x) in the as-cast state. darker interdendritic areas (\#2) were found to be enriched with $\mathrm{Ti}, \mathrm{Cr}$, and V (Table 2).

Relatively small amounts of $\mathrm{Al}$ and $\mathrm{Ni}$ in the $\mathrm{x}=5$ alloy resulted in a more complex microstructure of the alloy (Fig. 3c, d). An EBSD phase map (Fig. 3d) showed the formation of a substantial amount (13\%) of the $\sigma$-phase (\#3 in Fig. $3 c$ ) in the bcc phase matrix (\#1 - dendrites and $\# 2$ - interdendrites). The average bcc grain size was $20 \pm 9 \mu \mathrm{m}$; the elongated $\sigma$ particles had an irregular polygonal shape with the average width of $3 \pm 1 \mu \mathrm{m}$. A small amount of the $\mathrm{Ti}_{2} \mathrm{Ni}$ phase $(<1 \%)$ was also detected (\#4); the $\mathrm{Ti}_{2} \mathrm{Ni}$ particles are visible as black spots in the SEMBSE images. Both the $\sigma$ and $\mathrm{Ti}_{2} \mathrm{Ni}$ phases were predominantly located in the interdendritic areas (Fig. 3c), which were enriched with $\mathrm{Ti}$ and $\mathrm{Cr}$ (Table 2). The chemical composition of the $\mathrm{Ti}_{2} \mathrm{Ni}$ particles was rather close to the nominal stoichiometry (including, however, $\sim 3-6$ at.\% of the rest of the constitutive elements of the alloy). In turn, the $\sigma$-phase had a complex chemical composition which can be described as (Ti, $\mathrm{Cr}$, $\mathrm{Nb}, \mathrm{V})_{0.7}(\mathrm{Ni}, \mathrm{Al})_{0.3}$, with the dominant presence of $\mathrm{Ti}(44.5$ at.\%) and $\mathrm{Ni}$ (22.5 at.\%).

An increase in the percentage of $\mathrm{Al}$ in the $\mathrm{x}=7$ alloy did not result in drastic changes in the microstructure (Fig. 3e, f). However, the fraction of both the $\sigma$ (\#2 in Fig. 3e) and $\mathrm{Ti}_{2} \mathrm{Ni}(\# 3)$ phase particles increased substantially to $25 \%$ and $3 \%$, respectively. The average size of the $\sigma$ and $\mathrm{Ti}_{2} \mathrm{Ni}$ particles was $4 \pm 2 \mu \mathrm{m}$ and $1.0 \pm 0.7 \mu \mathrm{m}$, respectively. Note that the interdendritic area, which formed in the $\mathrm{x}=7$ alloy a continuous network, seemed to be fully consumed by the second phases, and only the dendritic bcc areas remained (\#1). The chemical compositions of the $\sigma$ and $\mathrm{Ti}_{2} \mathrm{Ni}$ phases were close to those in the previous alloy while the bcc phase became depleted of $\mathrm{Ni}$ and enriched in $\mathrm{Nb}$ (Table 2).

Even more complex microstructure was found in the alloy with the maximum amount of $\mathrm{Al}(\mathrm{x}=10)$ (Fig. $3 \mathrm{~g}, \mathrm{~h})$. Microstructure has a typical dendritic morphology, however only the dendritic areas were occupied by the bcc phase with the volume fraction of $31 \%$ (\#1 in Fig. $3 \mathrm{~g}$ ), while the interdendritic areas consisted of both the $\sigma$-phase $(60 \%, \# 2)$ and $\mathrm{Ti}_{2} \mathrm{Ni}(9 \%, \# 3)$ phase. The $\sigma$ phase particles formed a continuous network with discrete areas of the bcc and $\mathrm{Ti}_{2} \mathrm{Ni}$ phases. The chemical composition of the phases was similar to those in the previous alloys (Table 2).

\subsection{Structure of the alloys after annealing $\left(1000^{\circ} \mathrm{C}, 24 \mathrm{~h}\right)$}

Fig. 4 shows XRD patterns of the Ti-Nb-Cr-V-Ni-Al alloys with different $\mathrm{Al}$ content $(\mathrm{x})$ after annealing at $1000^{\circ} \mathrm{C}$ for $24 \mathrm{~h}$. One can clearly see that the annealing treatment did not change the phase composition of the alloys significantly: the $\mathrm{Ti}_{50} \mathrm{Nb}_{30} \mathrm{Cr}_{10} \mathrm{~V}_{10}$ alloy had the single bcc phase structure, while the addition of $\mathrm{Al}$ and $\mathrm{Ni}$ resulted in the appearance of the $\sigma$ and $\mathrm{Ti}_{2} \mathrm{Ni}$ phases. The intensity of the bcc peaks decreased with an increase in the $\mathrm{Al} / \mathrm{Ni}$ content. The lattice parameters of the phases were slightly affected by annealing (Supplementary information, Table S2). For example, the lattice constant of the bcc phase changed from $0.3225 \mathrm{~nm}$ in the $\mathrm{x}=0$ alloy to $0.3181-0.3185 \mathrm{~nm}$ in the $\mathrm{x}=5-10$ alloys (Table 4). The lattice parameters of the $\sigma$ and $\mathrm{Ti}_{2} \mathrm{Ni}$ phases also varied in a very limited interval (see Tables S1 and S2).

Both SEM-BSE images and EBSD IPF/phase maps of the alloy structure after annealing treatment are shown in Fig. 5. The $\mathrm{Ti}_{50} \mathrm{Nb}_{30} \mathrm{Cr}_{10} \mathrm{~V}_{10}$ alloy had a single-phase granular microstructure with a polygonal shape of the grains (Fig. 5a, b). The dendritic segregations were almost not observed in the microstructure (Fig. 5a). The average bcc grain size was $170 \pm 80 \mu \mathrm{m}$; the grain size became coarser while the scatter became lower in comparison with the as-cast state (Fig. 3a, b). The chemical composition of the bcc grains was close to the nominal composition of the alloys (Table 3).

Fig. $5 \mathrm{c}$, $\mathrm{d}$ shows the microstructure of the $\mathrm{x}=5$ alloy. The dendritic segregations in the bcc matrix disappeared after annealing (Fig. 5c). Inside the bcc matrix (\#1 in Fig. 5c), coarse, irregularly shaped particles of the $\sigma$-phase were found (Fig. 5d). These particles with the size of $4 \pm$ $1 \mu \mathrm{m}$ are dark-grey in the SEM-BSE image (\#2); the fraction of the 


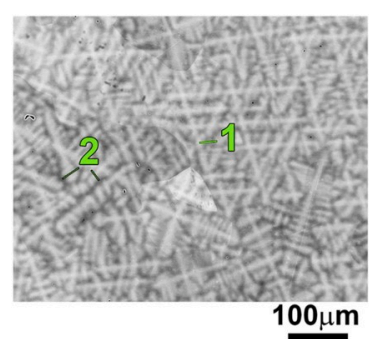

A

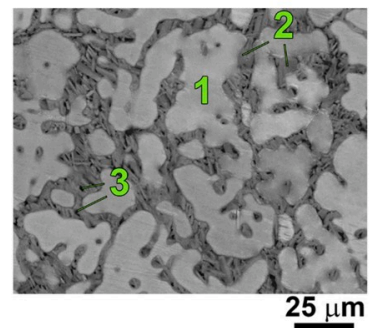

E

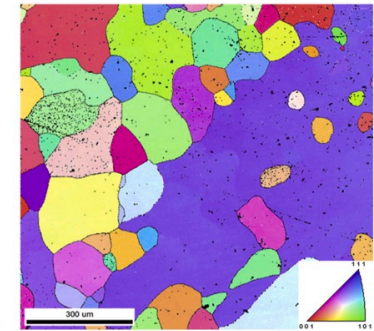

B

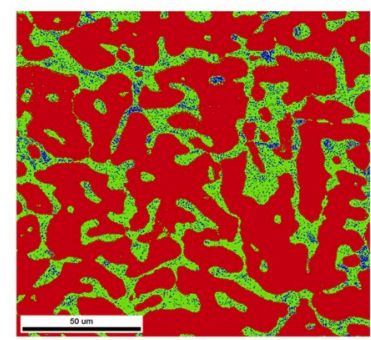

F

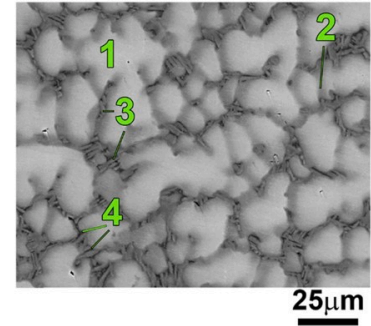

C

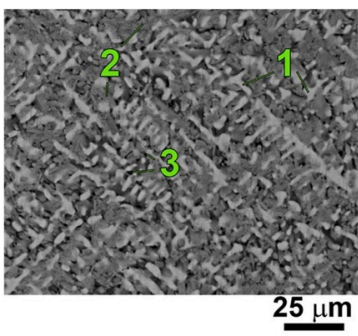

G

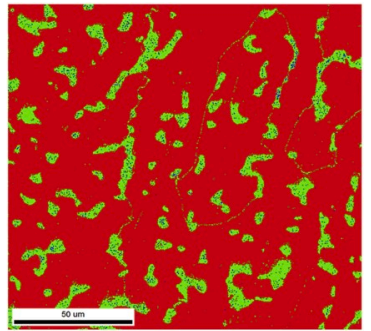

D

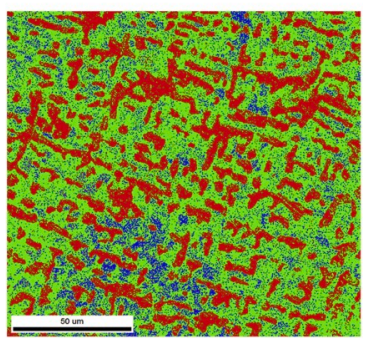

H

Fig. 3. Microstructure of the Ti-Nb-Cr-V-Ni-Al alloys with different Al contents in the as-cast state: $a, b-x=0 ; c, d-x=5 ; e, f-x=7 ; g, h-x=10$; $a, c, e, g-S E M-$ BSE images; $b$ - IPF map; d, f, $h$ - phase maps (red color - bcc; green $-\sigma$; blue $-\mathrm{fcc}\left(\mathrm{Ti}_{2} \mathrm{Ni}\right.$ ) phases). The chemical compositions of the constitutive phases are shown in Table 2. (For interpretation of the references to color in this figure legend, the reader is referred to the Web version of this article.)

Table 2

Chemical compositions of the structural constituents of the program Ti-Nb-Cr-V-Ni-Al alloys with different Al content ( $\mathrm{x}$ ) in the as-cast state. The corresponding phases are shown in Fig. 3.

\begin{tabular}{|c|c|c|c|c|c|c|c|c|c|c|c|c|c|}
\hline \multicolumn{2}{|c|}{ Elements, at.\% } & \multicolumn{2}{|l|}{$\mathrm{Ti}$} & \multicolumn{2}{|l|}{$\mathrm{Nb}$} & \multicolumn{2}{|l|}{$\mathrm{Cr}$} & \multirow[t]{2}{*}{$\mathrm{V}$} & \multirow[t]{2}{*}{$\mathrm{Ni}$} & \multicolumn{2}{|l|}{$\mathrm{Al}$} & \multicolumn{2}{|l|}{ Vf (\%) } \\
\hline Con & & $\mathrm{x}=0$ & & & & & & & & & & & \\
\hline № & Designation & & & & & & & & & & & & \\
\hline 1 & Bcc dendrite & 46.6 & 37.2 & & 7.1 & & 9.1 & & - & & - & & 100 \\
\hline 2 & Bcc interdendrite & 55.0 & 18.5 & & 14.9 & & 11.6 & & - & & - & & \\
\hline \multicolumn{2}{|c|}{ Alloy composition } & 50.0 & 28.9 & & 10.5 & & 10.6 & & - & & - & & - \\
\hline \multicolumn{2}{|c|}{ Nominal composition } & $\begin{array}{l}50 \\
x=5\end{array}$ & 30 & & 10 & & 10 & & - & & - & & - \\
\hline 1 & Bcc dendrite & 41.5 & & 29.2 & & 9.6 & & 11.0 & 3.4 & 5.3 & & 86 & \\
\hline 2 & Bcc interndendrite & 44.3 & & 22.7 & & 11.6 & & 10.9 & 4.9 & 5.6 & & & \\
\hline 3 & $\sigma$-phase & 44.5 & & 10.8 & & 9.0 & & 5.9 & 22.5 & 7.3 & & 13 & \\
\hline 4 & $\mathrm{Ti} 2 \mathrm{Ni}$ & 52.4 & & 6.6 & & 4.8 & & 3.4 & 26.4 & 6.4 & & $<1$ & \\
\hline \multicolumn{2}{|c|}{ Alloy composition } & 43.3 & & 22.8 & & 10.5 & & 9.8 & 7.9 & 5.7 & & - & \\
\hline \multicolumn{2}{|c|}{ Nominal composition } & $\begin{array}{l}42.2 \\
x=7\end{array}$ & & 25.3 & & 10.0 & & 10.0 & 7.5 & 5 & & - & \\
\hline 1 & Bcc phase & 40.4 & & 23.0 & & 11.3 & & 12.0 & 5.2 & 8.1 & & 72 & \\
\hline 2 & $\sigma$-phase & 39.4 & & 11.9 & & 10.3 & & 6.9 & 21.9 & 9.6 & & 25 & \\
\hline 3 & $\mathrm{Ti} 2 \mathrm{Ni}$ & 52.1 & & 7.3 & & 4.9 & & 3.8 & 25.6 & 6.3 & & 3 & \\
\hline \multicolumn{2}{|c|}{ Alloy composition } & 42.1 & & 20.1 & & 9.9 & & 9.7 & 10.4 & 7.8 & & - & \\
\hline \multicolumn{2}{|c|}{ Nominal composition } & $\begin{array}{l}39.1 \\
x=10\end{array}$ & & 23.4 & & 10.0 & & 10.0 & 10.5 & 7.0 & & - & \\
\hline 1 & Bcc phase & 32.3 & & 26.0 & & 11.7 & & 13.7 & 5.8 & 10.5 & & 31 & \\
\hline 2 & $\sigma$-phase & 31.7 & & 16.1 & & 10.8 & & 8.7 & 20.4 & 12.3 & & 60 & \\
\hline 3 & $\mathrm{Ti} 2 \mathrm{Ni}$ & 43.3 & & 10.3 & & 6.7 & & 5.9 & 23.2 & 10.6 & & 9 & \\
\hline \multicolumn{2}{|c|}{ Alloy composition } & 34.8 & & 18.7 & & 9.9 & & 9.8 & 15.6 & 11.2 & & - & \\
\hline \multicolumn{2}{|c|}{ Nominal composition } & 34.4 & & 20.6 & & 10.0 & & 10.0 & 15.0 & 10.0 & & - & \\
\hline
\end{tabular}

$\sigma$-phase was $11 \%$. Fine black particles (\#3) can be found inside the $\sigma$ particles or at the $\sigma / \mathrm{bcc}$ interfaces (Fig. $5 \mathrm{c}$ ); these black particles can be identified as the $\mathrm{Ti}_{2} \mathrm{Ni}$ phase based on the result of EBSD analysis (Fig. 5d). The fraction and average size of the $\mathrm{Ti}_{2} \mathrm{Ni}$ particles was $2 \%$ and $2.0 \pm 0.7 \mu \mathrm{m}$, respectively. The chemical compositions of the constitutive phases (Table 3) were quite close to those of the as-cast alloy (Table 2).

An increase in the $\mathrm{Al}$ content in the $\mathrm{x}=7$ alloy did result in an noticeable increase in the fraction of the second phases (Fig. 5e, f): the percentages of the $\sigma$ and $\mathrm{Ti}_{2} \mathrm{Ni}$ phases were $29 \%$ and $3 \%$, respectively. The $\sigma$ phase particles (\#2 in Fig. 5e) usually formed characteristic cellular conglomerates, however individual particles can also be found.
The $\mathrm{Ti}_{2} \mathrm{Ni}$ phase particles (\#3) were located either inside the $\sigma$ particles or at the $\sigma / \mathrm{bcc}$ interfaces. The transversal sizes of the $\sigma$ particles and bcc grains were $5 \pm 1 \mu \mathrm{m}$ and $2.0 \pm 0.6 \mu \mathrm{m}$, respectively. The chemical compositions of the phases are given in Table 3.

A continuous network of the $\sigma$ phase (\#2 in Fig. 5h) with a fraction of $65 \%$ was found in the alloy with 10 at.\% of Al (Fig. 5g, h). The bcc particles (\#1) with a fraction of $23 \%$ and the average size of $8 \pm 4 \mu \mathrm{m}$ were found inside the $\sigma$ matrix. In addition, relatively coarse (in comparison with the alloys with a lower content of $\mathrm{Al}$ ) $\mathrm{Ti}_{2} \mathrm{Ni}$ particles (\#3) with the size and fraction of $5 \pm 3 \mu \mathrm{m}$ and $12 \%$, respectively, were observed. The chemical compositions of the phases were similar to those in the alloys with a lower content of $\mathrm{Al}$ and were the same as in the as- 


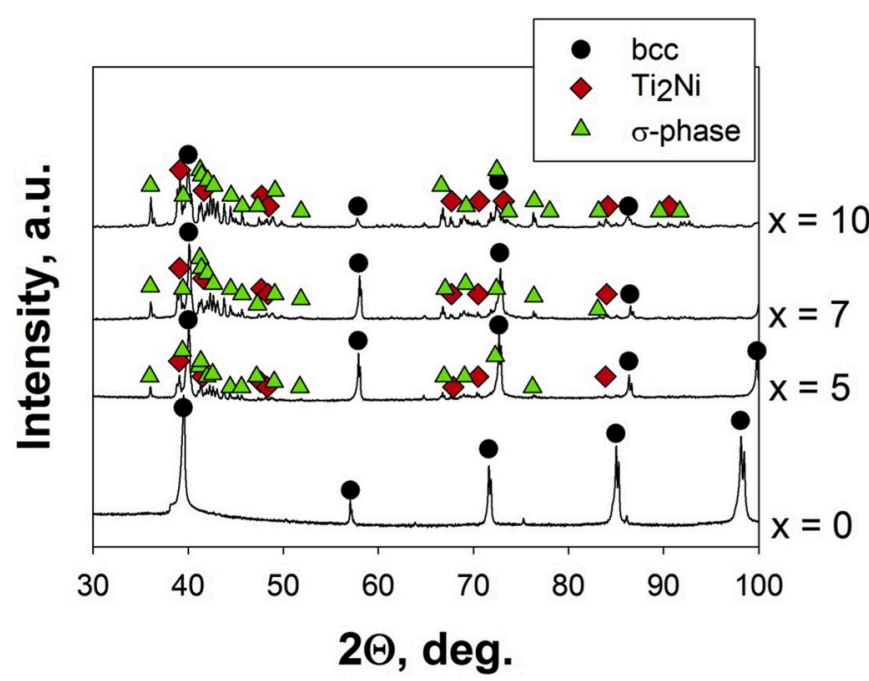

Fig. 4. XRD pattern of the Ti-Nb-Cr-V-Ni-Al alloys with different $\mathrm{Al}$ content (x) after annealing at $1000{ }^{\circ} \mathrm{C}$ for $24 \mathrm{~h}$.

cast alloy with 10 at.\% of $\mathrm{Al}$ (Tables 2 and 3).

\subsection{Mechanical properties}

Mechanical properties of the Ti-Nb-Cr-V-Ni-Al alloys in the as-cast and annealed conditions were evaluated during compression at room temperature or at $800{ }^{\circ} \mathrm{C}$. In both conditions the alloys demonstrated very similar mechanical behavior, thus only data for the annealed condition is presented here. The stress-strain curves obtained at room temperature and $800^{\circ} \mathrm{C}$ are shown respectively in Fig. $6 \mathrm{a}$ and b, while the obtained characteristics (yield strength $\left(\sigma_{\mathrm{YS}}\right)$, peak strength $\left(\sigma_{\mathrm{p}}\right)$, and compressive strain $(\varepsilon)$ ) are summarized in Table 4 . The data for the ascast condition can be found in Supplementary information (Fig. S1 and Table S3).

The annealed $\mathrm{Ti}_{50} \mathrm{Nb}_{30} \mathrm{Cr}_{10} \mathrm{~V}_{10}$ alloy had relatively low yield strength at room temperature (755 $\mathrm{MPa}$ ) however due to good strain hardening capacity the alloy did not fracture even after reaching $50 \%$ of height reduction (Fig. 6a). The addition of 5 at.\% of $\mathrm{Al}$ resulted in a slight increase in the yield strength to $775 \mathrm{MPa}$, while the peak strength was found to be $1240 \mathrm{MPa}$. Meanwhile ductility of the alloy decreased to $13.8 \%$ in this alloy. A considerable improvement in strength was obtained in the alloy with 7 at.\% of Al. In this case, the yield strength of $1600 \mathrm{MPa}$ was attained together with reasonable ductility of $8.9 \%$. Note that the apparent work hardening rate (i.e. the slope of the plastic deformation domain of the curve) all of the $\mathrm{x}=0-7$ alloys was almost identical. Meanwhile further increase in the $\mathrm{Al}$ concentration resulted in a complete loss in ductility; the $\mathrm{x}=10$ alloy has fractured in the elastic region at $1830 \mathrm{MPa}$.

An increase in the testing temperature to $800{ }^{\circ} \mathrm{C}$ resulted in considerable softening and a substantial improvement in ductility of the studied Ti-Nb-Cr-V-Ni-Al alloys (Fig. 6b). For example, the yield strength was $45,85,110$, or $285 \mathrm{MPa}$ for the alloys with $\mathrm{x}=0,5,7$ or 10 , respectively. All the alloys were deformed in compression to $50 \%$ of height reduction without fracture. However, shapes of the stress-strain curves differed from each other considerably depending on the Al concentration. The alloys with $\mathrm{x}=0-7$ demonstrated after yielding an extended stage nearly steady-state flow stage. Note that the $x=7$ alloy showed some signs of hardening at reduction $>10 \%$. The $\mathrm{x}=10$ alloy softened continuously during the plastic flow after yielding.

To get an additional insight into the mechanical behavior of the program alloys, nanohardness of the constitutive phases was measured in the annealed $\mathrm{x}=10$ alloy (Table 5 ). The bcc phase was found to be the softest one with the hardness of $530 \mathrm{HV}$, while the $\mathrm{Ti}_{2} \mathrm{Ni}$ phase was significantly harder (935 HV). However, the highest hardness demonstrated the $\sigma$-phase $(1085 \mathrm{HV})$.

Table 4

Compressive mechanical characteristics ( $\sigma_{\mathrm{YS}}$ - yield strength, $\sigma_{\mathrm{YS}}$ - peak strength, $\varepsilon$ - compressive strain) of the Ti-Nb-Cr-V-Ni-Al alloys with different $\mathrm{Al}$ content (x) after annealing at $1000{ }^{\circ} \mathrm{C}$ for $24 \mathrm{~h}$ obtained at RT or $800^{\circ} \mathrm{C}$.

\begin{tabular}{llll}
\hline Alloy & $\sigma_{\mathrm{YS}}, \mathrm{MPa}$ & $\sigma_{\mathrm{p}}, \mathrm{MPa}$ & $\varepsilon, \%$ \\
\hline $\mathrm{RT}$ & & & \\
$\mathrm{x}=0$ & 755 & - & $\geq 50$ \\
$\mathrm{x}=5$ & 775 & 1135 & 13.8 \\
$\mathrm{x}=7$ & 1270 & 1685 & 8.9 \\
$\mathrm{x}=10$ & - & 1395 & 0 \\
$800{ }^{\circ} \mathrm{C}$ & & & \\
$\mathrm{x}=0$ & 45 & 60 & $\geq 50$ \\
$\mathrm{x}=5$ & 85 & 105 & $\geq 50$ \\
$\mathrm{x}=7$ & 110 & 200 & $\geq 50$ \\
$\mathrm{x}=10$ & 285 & 395 & \\
\hline
\end{tabular}

Table 3

Chemical compositions of the structural constituents of the program Ti-Nb-Cr-V-Ni-Al alloys with the different $\mathrm{Al}$ content ( $\mathrm{x}$ ) after annealing at $1000{ }^{\circ} \mathrm{C}$ for $24 \mathrm{~h}$. The corresponding phases are shown in Fig. 5.

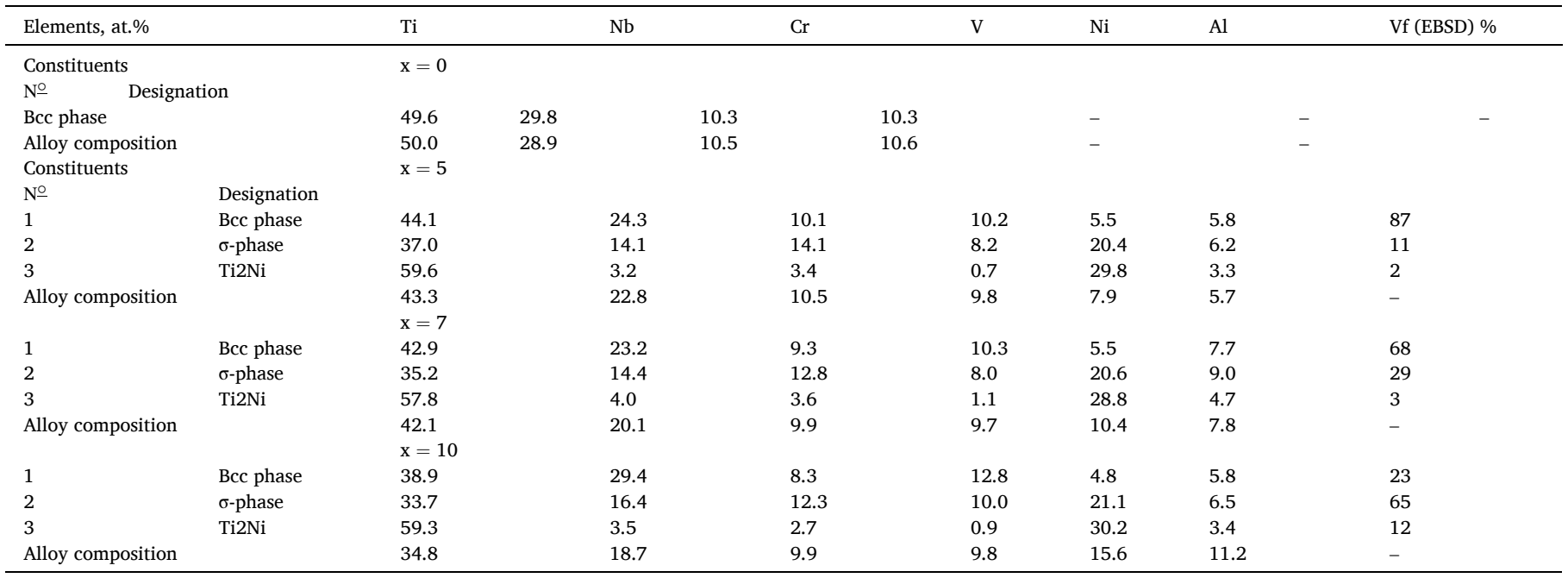




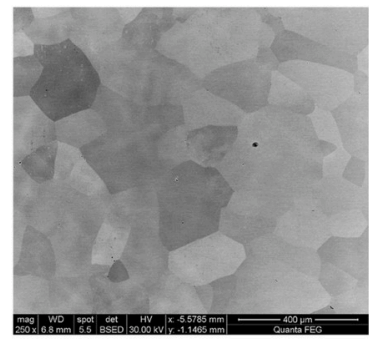

A

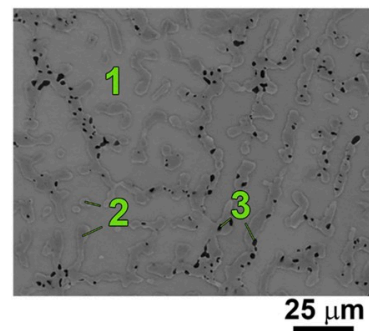

E

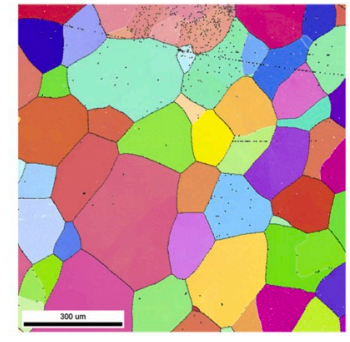

B

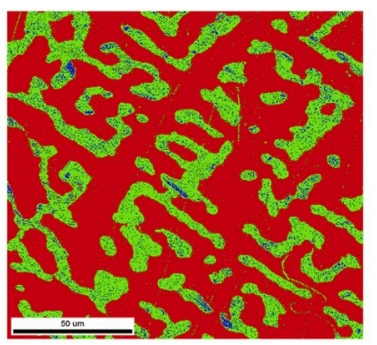

F

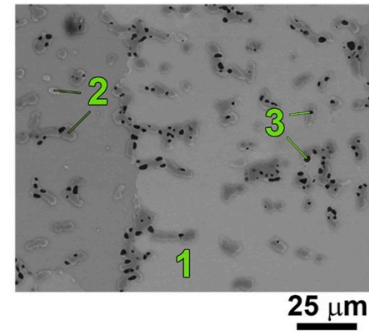

C

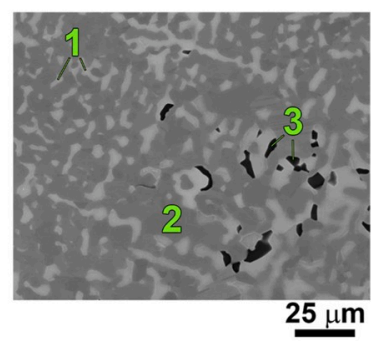

G

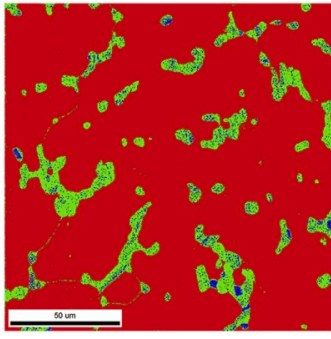

D

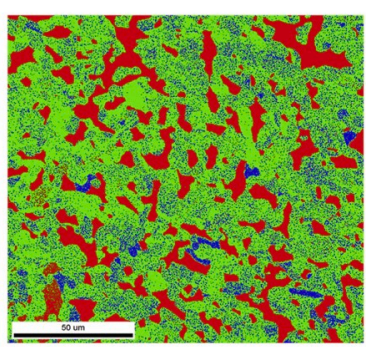

H

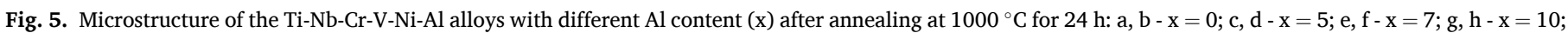

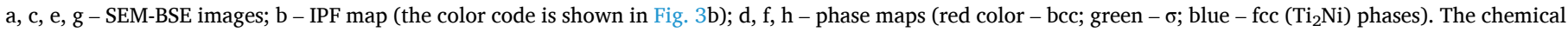

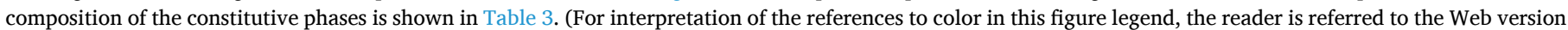
of this article.)

\subsection{Structure after deformation at $800{ }^{\circ} \mathrm{C}$}

Structures of the $\mathrm{x}=0$ and $\mathrm{x}=10$ alloys after compression to $50 \%$ height reduction at $800{ }^{\circ} \mathrm{C}$ are shown in Fig. 7. XRD did not reveal any changes in the phase composition of the alloys after hot deformation (Fig. 7a): the $\mathrm{x}=0$ alloy was composed of the single bcc phase and $\mathrm{x}=$ 10 alloy contained a mixture of the bcc, $\sigma$, and $\mathrm{Ti}_{2} \mathrm{Ni}$ phases. The deformed microstructure of the $\mathrm{x}=0$ alloy consisted of characteristic pancake-shaped grains (Fig. 7b). Inside some grains, a well-developed substructure without any signs of dynamic recrystallization was observed. In the $x=10$ alloy the bcc phase ( $\# 1$ in Fig. $7 \mathrm{c}$ ), most probably acting as a "soft" layer between hard particles of the $\sigma$-phase, accommodated a large amount of plastic strain. However, the morphology of the $\sigma$-phase particles (\#2) also implies their participating in the plastic flow. The characteristic continuous network of the $\sigma$-phase in the initial (annealed at $1000^{\circ} \mathrm{C}$ (Fig. $5 \mathrm{~g}$ and h)) condition broke during deformation so that individual $\sigma$ particles aligned with the metal flow direction and separated by the bcc layers were found. The $\mathrm{Ti}_{2} \mathrm{Ni}$ particles (\#3) seemed to be not affected significantly by the deformation.

\section{Discussion}

\subsection{Phase composition and microstructure of the Ti-Nb-Cr-V-Ni-Al alloys}

The obtained results show a significant effect of the chemical composition (i.e. a decrease in the concentration of $\mathrm{Ti}$ and $\mathrm{Nb}$ and an increase in the content of $\mathrm{Ni}$ and $\mathrm{Al}$ in the $\mathrm{Ti}_{(50-1.5625 \mathrm{x})} \mathrm{Nb}_{(30-}$ ${ }_{0.9375 \mathrm{x})} \mathrm{Cr}_{10} \mathrm{~V}_{10} \mathrm{Ni}_{1.5 \mathrm{x}} \mathrm{Al}_{\mathrm{x}}(\mathrm{x}=0,5,7,10)$ alloys) on microstructure of the program alloys in the as-cast and annealed $\left(1000{ }^{\circ} \mathrm{C}\right)$ conditions. An increase in $\mathrm{x}$ resulted in the formation of the Ti, Ni-rich $\sigma$, and $\mathrm{Ti}_{2} \mathrm{Ni}$ phases rather than the $\mathrm{B} 2 \mathrm{Ni}$-rich phase which was anticipated from the enthalpies of the intermetallic phases formation [41] and CALPHAD predictions (Fig. 1). The additional phases formation can be expected since Ti and Nb are known to be bcc phase stabilizers in RHEAs [2,43], while $\mathrm{Al}$ is a compound former, at least in certain combinations of elements [43-45]. However, no experimental information on the effect of $\mathrm{Ni}$ on the structure and properties of RHEAs was available before.
The equilibrium phase diagram, constructed for the $\mathrm{Ti}_{(50-}$ ${ }_{1.5625 \mathrm{x})} \mathrm{Nb}_{(30-0.9375 \mathrm{x})} \mathrm{Cr}_{10} \mathrm{~V}_{10} \mathrm{Ni}_{1.5 \mathrm{x}} \mathrm{Al}_{\mathrm{x}}$ with $\mathrm{x}=0-10$ (Fig. 1) suggested the bcc solid solution formation during solidification with possible precipitation of the fcc solid solution, Ni-rich B2 phase, and C14/C15 Laves phases during further cooling. The solvus temperatures of the fcc solid solution and the Laves phase were well below $1000{ }^{\circ} \mathrm{C}$. Therefore, it is not surprising that these phases were not found in the as-cast state and after annealing at $1000^{\circ} \mathrm{C}$. The solvus temperature and the fraction of the $\mathrm{B} 2$ phase quickly increased with an increase in $\mathrm{x}$, and the alloys with $x>7$ were supposed to contain B2 phase in solid-state always. However, the B2 phase was also not detected even in the alloy with $\mathrm{x}=$ 10. Instead the $\sigma$-phase and a small portion of the $\mathrm{Ti}_{2} \mathrm{Ni}$ phase appeared in the $\mathrm{x}=5$ alloy; their fraction increased with a further increase in $\mathrm{x}$ (Figs. 2-5). Thus, the ThermoCalc calculations correctly predicted a single bcc solid solution structure of the $\mathrm{Ti}_{50} \mathrm{Nb}_{30} \mathrm{Cr}_{10} \mathrm{~V}_{10}$ alloy (it worth noting that no additional phases were found in the alloy after deformation at $800^{\circ} \mathrm{C}$ (Fig. 8a) which is also consistent with the phase diagram) and the formation of a second phase(s) with the addition of $\mathrm{Al}$ and $\mathrm{Ni}$; however the exact type of these phases cannot be reliably determined by this method.

It is already well established that the accuracy of the CALPHAD predictions is critically dependent on the validity of the thermodynamic databases used $[46,47]$. A full thermodynamic description of each binary and ternary phase diagram belonging to the multicomponent system is required for the accurate calculation. For example, the senary Al-Cr-Nb-Ni-Ti-V system contains 15 binary and 20 ternary systems. The TCHEA3 database used in the current study contained a full description of 15 binaries for this system [48] which means that the fraction of the accessed binaries (FAB; [46]) was equal to 1 . However, out of 20 ternaries, only 6 were fully accessed, and 11 were accessed fully or tentatively. This means that the fraction of the accessed ternaries (FAT; [46]) was 0.3-0.55. Given relatively low accuracy of the predicted phase diagram in the current case (Fig. 1), one can conclude that a high $\mathrm{FAB}$ is not enough because a higher FAT is required to get more accurate predictions, which is in agreement with some recent results [49].

Since it was not predicted by the Thermo-Calc software, the available information from binary and ternary phase diagrams [50,51] was also analyzed to get more clues on the $\sigma$-phase formation. Among the 15 

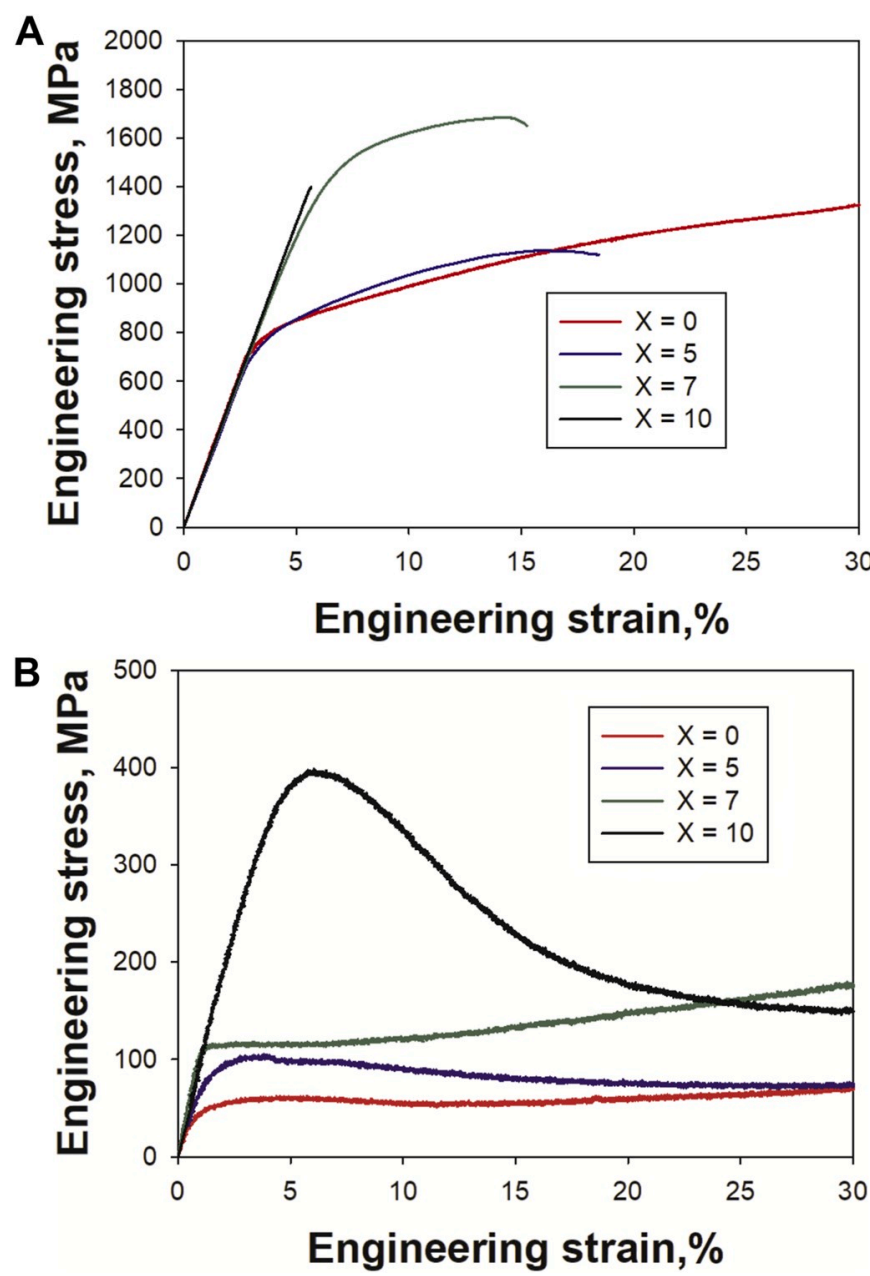

Fig. 6. Engineering stress-strain curves obtained during compression at RT (a) or at $800{ }^{\circ} \mathrm{C}(\mathrm{b})$ of the Ti-Nb-Cr-V-Ni-Al alloys with different $\mathrm{Al}$ content ( $\mathrm{x}$ ) after annealing at $1000{ }^{\circ} \mathrm{C}$ for $24 \mathrm{~h}$.

Table 5

Nanohardness of the constitutive phases of the $\mathrm{Ti}_{34.4} \mathrm{Nb}_{20.6} \mathrm{Cr}_{10} \mathrm{~V}_{10} \mathrm{Ni}_{15} \mathrm{Al}_{10}(\mathrm{x}=10)$ alloy after annealing at $1000^{\circ} \mathrm{C}$ for $24 \mathrm{~h}$.

\begin{tabular}{ll}
\hline Phase & Hanohardness, HV \\
\hline bcc & $530 \pm 20$ \\
$\mathrm{Ti}_{2} \mathrm{Ni}$ & $935 \pm 70$ \\
$\sigma$-phase & $1085 \pm 25$ \\
\hline
\end{tabular}

binaries, only 2 contained information about the $\sigma$-phase: Al-Nb and $\mathrm{Ni}-\mathrm{V}$. In the Al-Nb system the $\sigma$-phase had quite a narrow homogeneity region around $70 \%$ of $\mathrm{Nb}\left(\mathrm{AlNb}_{2}\right)$, while in the $\mathrm{Ni}-\mathrm{V}$ system the $\mathrm{V}$ concentration was in the range of $55-75 \%\left(\mathrm{NiV}_{2}\right)$. In the ternary systems, 8 phase diagrams contained information on the $\sigma$-phase: Al-Cr-Nb, Al-Nb-Ni, Al-Nb-Ti, Al-Nb-V, Al-Ni-V, Cr-Ni-V, Nb-Ni-V and Ni-Ti-V. All 8 ternaries included either $\mathrm{Al}-\mathrm{Nb}$ or $\mathrm{Ni}-\mathrm{V}$ binary. The $\mathrm{AlNb}_{2}$ $\sigma$-phase was able to dissolve up to $\sim 30$ at. $\%$ of $\mathrm{Ti}$ or $\sim 20 \%$ of $\mathrm{V}$, while the $\mathrm{NiV}_{2} \sigma$-phase generally dissolved only $\sim 10$ at.\% of a third component. It also should be mentioned that the existence of the $\sigma$-phase in the Cr-Ni binary system was sometimes reported [52], yet these claims were criticized therefore the $\sigma$-phase is not believed to be an equilibrium phase in the $\mathrm{Cr}$-Ni system [53]. Also note that the $\mathrm{Ti}_{2} \mathrm{Ni}$ phase is present in the Ni-Ti binary and the Ni-Ti-Y $(\mathrm{Y}=\mathrm{Al}, \mathrm{Cr}, \mathrm{Nb}, \mathrm{V})$ ternary phase diagrams. These phase diagrams suggest quite a narrow homogeneity range which agrees with the chemical composition close to the stoichiometric one found experimentally in the present Al-Cr-Nb-Ni-Ti-V alloys (Tables 2 and 3).

The binary and ternary phase diagrams suggested that the $\sigma$-phase in the Al-Cr-Nb-Ni-Ti-V alloys can be either of an $\mathrm{AlNb}_{2}$ or $\mathrm{NiV}_{2}$ type; the $\mathrm{AlNb}_{2}$ type $\sigma$-phase has already been reported in some Al-Cr-Nb-Ti-V RHEAs [16,25]. However, in the examined $\mathrm{Ti}_{(50-1.5625 \mathrm{x})} \mathrm{Nb}_{(30-0.9375 \mathrm{x})} \mathrm{Cr}_{10} \mathrm{~V}_{10} \mathrm{Ni}_{1.5 \mathrm{x}} \mathrm{Al}_{\mathrm{x}}(\mathrm{x}=5,7,10)$ the $\sigma$-phase was $\mathrm{Ti}$, Ni-rich which is approximately corresponding to the (Ti, Cr, Nb, $\mathrm{V})_{0.7}(\mathrm{Ni}, \mathrm{Al})_{0.3}$ stoichiometry. This phase: (i) cannot be anticipated from the Ni-Ti binary and Ni-Ti-Y ( $\mathrm{Y}=\mathrm{Al}, \mathrm{Cr}, \mathrm{Nb}, \mathrm{V})$ ternaries; (ii) was never reported in the literature. The formation of the Ti, Ni-based $\sigma$-phase in the program alloys can be attributed to both the intricacies of chemical composition and complex interaction of the constitutive elements that stabilize new phases, unexpected from the lower order phase diagrams. However, additional experiments are required to establish the stability of the observed Ti, Ni-rich $\sigma$-phase.

An increase in the $\mathrm{Al}$ (and $\mathrm{Ni}$ ) percentage had resulted in a considerable increase in the fraction of the Ti, Ni-rich $\sigma$-phase. For instance, the amount of the $\sigma$ particles was $11-13 \%$ and $60-65 \%$ in the $x=5$ and $x=$ 10 alloys, respectively (Tables 2 and 3). Furthermore, the sum of the atomic percentages of $\mathrm{Al}$ and $\mathrm{Ni}$ in the $\sigma$ particles was almost constant (29.8-32.7 at.\% in the as-cast condition and $26.6-29.6$ at.\% in the annealed condition (Tables 3 and 5)) irrespective of the composition of the alloys. In addition, the total concentration of $\mathrm{Al}$ and $\mathrm{Ni}$ in the bcc phase in the annealed condition was also almost constant (10.6-13.2 at. $\%)$. However, in the as-cast condition much more significant scatter was found (from 9.6 at. $\%$ in the $\mathrm{x}=5$ alloy to 16.3 at. $\%$ in the $\mathrm{x}=10$ alloy) most probably due to the non-equilibrium nature of the phases produced during solidification. It therefore seems that the $\mathrm{x}=5$ composition (i.e. 5 at.\% of $\mathrm{Al}$ and 7.5 at.\% of $\mathrm{Ni}$ ) is very close to the border between the bcc and bcc $+\sigma$ phase fields and the alloys with a lower amount of $\mathrm{Al}$ and Ni should most probably have a single bcc phase structure.

Since the solubility of $\mathrm{Al}$ and $\mathrm{Ni}$ in both the bcc and $\sigma$ phases is fixed
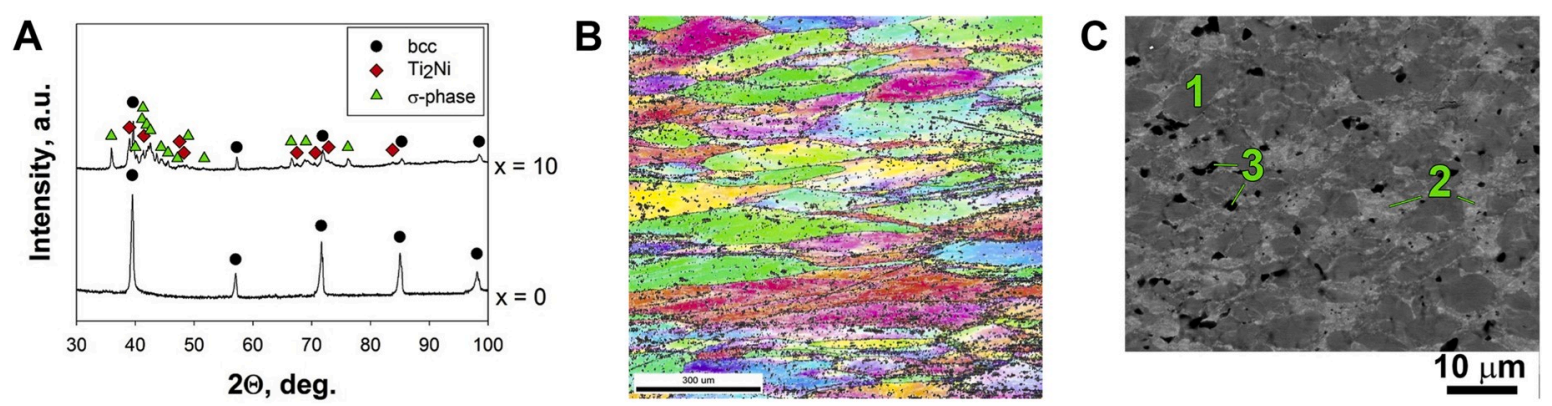

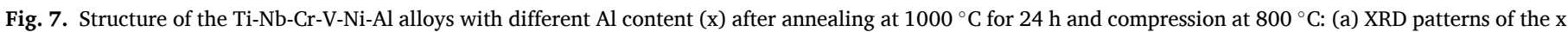

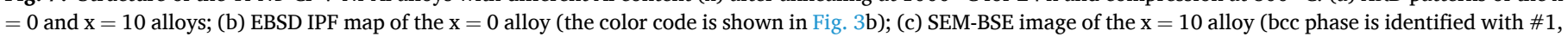

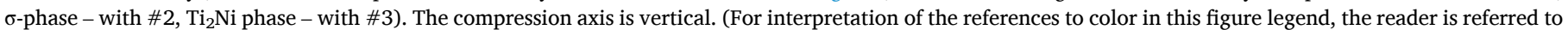
the Web version of this article.) 

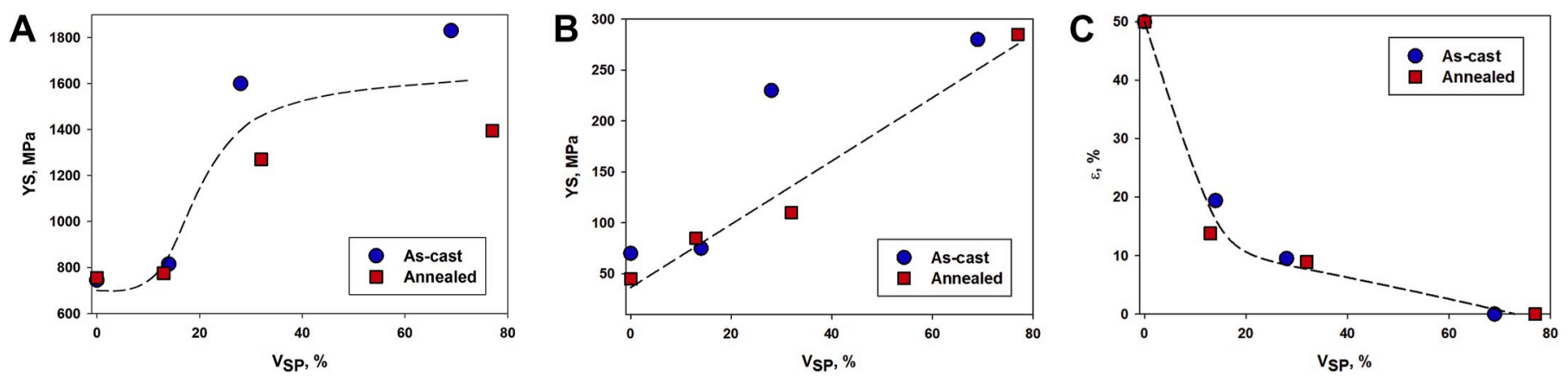

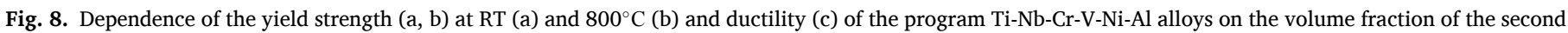
phases. Dashed lines are only guides to eyes. In the case of $\mathrm{x}=10$ alloy the peak strength was used instead of the yield strength at RT.

(at least in a rather equilibrium annealed condition), the amount of the $\sigma$-phase in the alloy is ought to be controlled by the total amount of Al and $\mathrm{Ni}$ in accordance with the lever rule. It worth noting that a similar dependence was earlier reported for $\mathrm{CoCrFeMnNiV}_{\mathrm{x}} \mathrm{HEAs}$ composed of the fcc and $\sigma$ phases $[36,54]$. Calculation of the bcc and $\sigma$ phases fractions using the $\mathrm{Al}$ and $\mathrm{Ni}$ concentrations both in the respective phases and in the corresponding alloy as per data in Tables 2 and 3, gave the fractions of the bcc phase of 85,70 and $15 \%$ in the $x=5,7$, and 10 alloys, respectively. The obtained values are reasonably close to the measured fractions $(87,68$, and $23 \%$, respectively; Table 3$)$. A good correlation between the predicted and measured values confirms that the fraction of the phases in the $\mathrm{Ti}_{(50-1.5625 \mathrm{x})} \mathrm{Nb}_{(30-0.9375 \mathrm{x})} \mathrm{Cr}_{10} \mathrm{~V}_{10} \mathrm{Ni}_{1.5 \mathrm{x}-}$ $\mathrm{Al}_{\mathrm{x}}$ alloys can be estimated using the lever rule. This gives the opportunity to tailor the structure and properties of the alloys by adjusting their chemical composition.

Meanwhile structure of the program alloys was found to be dependent on the annealing treatment also. The initial as-cast alloys consisted of the bcc phase with dendritic segregations (Fig. 3a, c, e). The interdendritic areas are expected to be enriched with "less refractory" elements (i.e. Al, $\mathrm{Ni}$ or Ti) like, for example, in the $\mathrm{x}=0$ alloy (Table 2). However, in the $x=5$ alloy the interdendritic areas were rich in Ti but depleted of $\mathrm{Al}$ and $\mathrm{Ni}$ (Table 2). Most probably, this is the result of the $\mathrm{Ni}$ and $\mathrm{Al}$ partitioning between the $\sigma$ and $\mathrm{Ti}_{2} \mathrm{Ni}$ phases. It is reasonable to suggest that immediately after solidification the interdendritic areas were enriched with $\mathrm{Al}$ and $\mathrm{Ni}$, but these elements were consumed during precipitation of the secondary phases through solid-state reactions. The morphology of the particles and the difference between their crystal structure and the structure of the "parent" bcc phase suggest that their nucleation was heterogeneous, and the growth occurred via a diffusioncontrolled mechanism predominantly inside interdendritic areas. The preferred location of the $\mathrm{Ti}_{2} \mathrm{Ni}$ particles suggests that they have a lower solvus temperature than that of the $\sigma$-phase and thus the $\mathrm{Ti}_{2} \mathrm{Ni}$ phase formed later. Initial enrichment of the interdendritic areas with $\mathrm{Al}$ and $\mathrm{Ni}$ is probably the reason why they serve as the preferred places for the $\sigma$ and $\mathrm{Ti}_{2} \mathrm{Ni}$ phases formation. It appears that a similar scenario is proper for $\mathrm{x}=7$ alloy, but the interdendritic areas in this case were completely consumed by the $\sigma$ and $\mathrm{Ti}_{2} \mathrm{Ni}$ phases. Although the structure of the ascast $\mathrm{x}=10$ alloy is quite complex, the bcc phase had a dendritic morphology (Fig. 3h) which might be an indicator of a similar phase transformation sequence.

The annealing treatment had resulted in only moderate changes in microstructure (Fig. 5). An obvious and well-anticipated annealing effect in the $\mathrm{Ti}_{50} \mathrm{Nb}_{30} \mathrm{Cr}_{10} \mathrm{~V}_{10}$ and $\mathrm{x}=5$ alloys was associated with the dendritic segregation disappearance (Fig. $5 \mathrm{a}$ and c). In addition, in the alloys containing the $\sigma$ and $\mathrm{Ti}_{2} \mathrm{Ni}$ phases $(\mathrm{x}=5$ and $\mathrm{x}=7$; Fig. $5 \mathrm{c}$ and $\mathrm{e}$, respectively) the second phases particles became somewhat coarser and attained more regular shape due to coalescence process in comparison with the as-cast condition (Fig. $3 \mathrm{c}$ and e). It also appears that an increase in the fraction of the second phases (in the $\mathrm{x}=7$ alloy, for example) was mostly associated with the already existing particles growth rather than with the precipitation of new finer particles. Meanwhile structure of the $\mathrm{x}=10$ alloy (Fig. $5 \mathrm{~g}$ ) was even more stable than that of the rest of the alloys, most probably because of slow diffusion through the $\sigma$ matrix.

Use of transition metals was recently proposed as a promising alloying strategy to improve properties of RHEA [55], yet it was never explored before. The current study suggests rather an unexpected result in the case of simultaneous usage of $\mathrm{Ti}$ (one of the most frequent elements of RHEAs [2]) and Ni so far. The coarse incoherent $\sigma$ and $\mathrm{Ti}_{2} \mathrm{Ni}$ particles appeared instead of anticipated, presumably fine and coherent B2 particles. Nevertheless, the obtained data shows that chemically complex RHEAs can contain phases that cannot be expected from the binary and ternary phase diagrams in contrast to some previous results [56]. This finding can open a new way to develop alloys with unexpected, novel phases.

\subsection{Relationships between structure and mechanical properties}

Mechanical properties at both room and elevated $\left(800{ }^{\circ} \mathrm{C}\right)$ temperatures strongly depended on the chemical composition and microstructure of the $\mathrm{Ti}_{(50-1.5625 \mathrm{x})} \mathrm{Nb}_{(30-0.9375 \mathrm{x})} \mathrm{Cr}_{10} \mathrm{~V}_{10} \mathrm{Ni}_{1.5 \mathrm{x}} \mathrm{Al}_{\mathrm{x}}(\mathrm{x}=0,5,7$, 10) alloys, (i.e. on the $\mathrm{Ti}, \mathrm{Nb}, \mathrm{Ni}$, and $\mathrm{Al}$ concentration; Fig. 6, S1 and Table 4, S3). The most pronounced changes in the microstructure were related to the secondary $\sigma$ and $\mathrm{Ti}_{2} \mathrm{Ni}$ phases formation, and the amount of these phases and their morphology changed significantly with variations in the chemical composition. Since the $\sigma$ and $\mathrm{Ti}_{2}$ phases were much harder than the bcc matrix of the initial $\mathrm{Ti}_{50} \mathrm{Nb}_{30} \mathrm{Cr}_{10} \mathrm{~V}_{10}$ alloy (Table 5), compression mechanical properties of the alloy were likely to be related to the fraction of secondary phases. Dependences of the yield strength at room temperature or at $800^{\circ} \mathrm{C}$ and compression ductility at room temperature on the fraction of the $\sigma$ and $\mathrm{Ti}_{2} \mathrm{Ni}$ phases are shown in Fig. 8. Note that (i) the second phases were mostly represented by the $\sigma$-phase with the ratio between the fractions of the $\mathrm{Ti}_{2} \mathrm{Ni}$ and $\sigma$ phases of $\sim 1: 5-1: 10$; (ii) ductility at $800^{\circ} \mathrm{C}$ are not plotted since all the alloys were compressed to the same strain level $(\geq 50 \%)$.

One can clearly see that indeed both strength and ductility of the alloys show pronounced dependence on the fraction of the $\sigma$ and $\mathrm{Ti}_{2} \mathrm{Ni}$ phases, yet the shape of these dependencies was different. For instance, at room temperature the yield strength demonstrated a sigmoidal type curve on the fraction of the phases (Fig. 8a). This type of dependence can be interpreted in the following way. When the fraction of the second phase particles is low (i.e. like $13-14 \%$ in the $x=5$ alloy), they are rather coarse, many of them are located at the grain boundaries, and therefore they do not act as effective obstacles for the dislocations moving in the bcc matrix. Meanwhile when their fraction increases (to $28-32 \%$ in the $x=7$ alloy), the coarse particles start to form a continuous network (Figs. 3f and 5f). In this case, they decrease the free dislocation path in the bcc matrix and therefore increased the strength of the alloys. Finally, when the fraction of the particles increases further (to $69-77 \%$ in the $x=10$ alloy), weak dependence of strength on the fraction of the particles was observed. Note that the transition occurred 
at the volume fraction of the second phases $\sim 50 \%$, i.e. when $\sigma$ became the matrix phase. It is likely that deformation in this case is controlled by processes in the $\sigma$-phase, and the fraction of the softer bcc solid solution does not affect strength of the alloy. Note that a similar type of behavior was recently reported for Fe-Mn-Cr-Ni-Al TMHEAs composed of a softer fcc and harder bcc + B2 phases [33].

However, test points scattering in the case of a similar volume fraction of the second phases (evident at $V_{f}>30 \%$ ) in Fig. 8a implies that other factors also contribute to the properties. One of the factors is the particle morphology. For example, in the as-cast $x=7$ alloy the bcc areas are often surrounded completely by the $\sigma$ particles (Fig. 3f), thus limiting the possibilities to transfer slip from one bcc grain/area to another. Instead, in the same alloy in the annealed condition the $\sigma$-phase existed in the form of individual particles or complex shape conglomerates surrounded by the continuous bcc matrix. Most probably these differences were responsible for the higher strength of the as-cast alloy despite the similar fractions of the $\sigma$-phase in both conditions (Fig. 8a). Besides the morphology of the phases, the grains/particles size and the variations in chemistry (Figs. 3 and 5, Tables 3 and 5) can be responsible for differences in mechanical properties (strength and ductility at room and elevated temperatures (Fig. 8)) between the as-cast and annealed conditions. The detailed analysis is required to elucidate the exact factors which govern the mechanical behavior of each alloy, which is beyond the scope of the current paper, however.

The $\sigma$ phase is known to be extremely brittle judging by the experience from conventional metallic alloys $[57,58]$. The available data on TMHEAs [59-61] and RHEAs [25] also confirmed a drastic decrease in ductility due to this phase. The results obtained in the current study agree with the previous reports; a pronounced decrease in ductility with an increase in the fraction of the second phases (mostly, $\sigma$ ) particles was observed (Fig. 8c). The dependence of ductility on the second phase particle fraction was not linear, however. It appears that at a relatively low $\sigma$-phase fraction when the ductile bcc solid solution phase was the matrix ( $x=5-7$ alloys), the $\sigma$ particles served as a preferred point for the crack nucleation and propagation and therefore an increase in their fraction reduced ductility considerably. When the $\sigma$-phase became the matrix phase ( $x=10$ alloy), the alloy fractured already during the elastic part of the curve due to the high brittleness of the phase (Fig. 6a).

Finally, the strength of the alloys at $800^{\circ} \mathrm{C}$ demonstrated an almost linear dependence on the fraction of the second phases (Fig. 8b). This is most likely because of the significant softening of the bcc phase, which results in very low strength of both the $\mathrm{Ti}_{50} \mathrm{Nb}_{30} \mathrm{Cr}_{10} \mathrm{~V}_{10}$ and $\mathrm{x}=5$ alloys (Fig. 6b). Only the presence of harder second phase particles with a significant fraction resulted in pronounced strengthening. However, even the $\mathrm{x}=10$ alloy with $60-65 \%$ of the $\sigma$-phase demonstrates only moderate strength of $280-285 \mathrm{MPa}$ at $800{ }^{\circ} \mathrm{C}$, which is quite low in regards to typical RHEAs properties [2]. The linear approximation of the available data suggests that the alloy fully composing of the $\sigma$ (mostly) and $\mathrm{Ti}_{2} \mathrm{Ni}$ phases should have strength of only $\sim 350 \mathrm{MPa}$ at $800^{\circ} \mathrm{C}$. This estimation shows that the $\sigma$-phase also loses its strength at $800{ }^{\circ} \mathrm{C}$. The confirmation of this assumption can be found in the post-deformation microstructure of the $\mathrm{x}=10$ alloy (Fig. 7c), which shows the $\sigma$ particles that clearly undergone plastic deformation. Gradual involvement of the $\sigma$-phase particles in plastic flow can result in a decrease in flow stress, observed at the stress-strain curves for the $\mathrm{x}=10$ alloy (Fig. 6b).

In summary, the obtained results suggest that the $\mathrm{Ti}$, Ni-rich $\sigma$-phase strengthens the $\mathrm{Ti}_{(50-1.5625 \mathrm{x})} \mathrm{Nb}_{(30-0.9375 \mathrm{x})} \mathrm{Cr}_{10} \mathrm{~V}_{10} \mathrm{Ni}_{1.5 \mathrm{x}} \mathrm{Al}_{\mathrm{x}}(\mathrm{x}=0,5,7$, 10) alloys significantly at room temperature, yet the $\sigma$ particles also results in a loss in ductility. Note that proper microstructure control via thermomechanical processing can most probably result in a more balanced combination of the properties [62-64]. Meanwhile, the $\sigma$ phase particles do not provide sufficient strengthening at $800{ }^{\circ} \mathrm{C}$. Further studies are required to establish the temperature interval where the $\mathrm{Ti}, \mathrm{Ni}$-rich $\sigma$-phase reinforced alloys retain their strength.

\section{Conclusions}

In this study, the as-cast and annealed structures of the $\mathrm{Ti}_{(50-}$ $1.5625 \mathrm{x}) \mathrm{Nb}_{(30-0.9375 \mathrm{x})} \mathrm{Cr}_{10} \mathrm{~V}_{10} \mathrm{Ni}_{1.5 \mathrm{x}} \mathrm{Al}_{\mathrm{x}}(\mathrm{x}=0,5,7,10)$ refractory high entropy alloys and compression mechanical properties were analyzed and the following conclusions were drawn:

1) $\mathrm{The} \mathrm{Ti}_{50} \mathrm{Nb}_{30} \mathrm{Cr}_{10} \mathrm{~V}_{10}$ had a single bcc phase structure in the as-cast and annealed conditions and after deformation at $800^{\circ} \mathrm{C}$ in agreement with ThermoCalc predictions. The gradual replacement of $\mathrm{Ti}$ and $\mathrm{Nb}$ with $\mathrm{Al}$ and $\mathrm{Ni}$ resulted in the formation of the coarse $\mathrm{Ti}, \mathrm{Ni}$ rich $\sigma$ and $\mathrm{Ti}_{2} \mathrm{Ni}$ phases. The fraction of the $\sigma$-phase increased considerably from $11-13 \%$ in the $\mathrm{x}=5$ alloy to $60-65 \%$ in the $\mathrm{x}=10$ alloy while the respective fractions of $\mathrm{Ti}_{2} \mathrm{Ni}$ were $1-2 \%$ and $9-12 \%$, respectively. Annealing changed the morphology of the microstructure but barely affected the amounts of the constitutive phases.

2) The Ti, Ni-rich $\sigma$-phase formation was never reported before and it is not anticipated based both on the equilibrium phase diagrams obtained by the ThermoCalc software (which predicted the formation of a Ni-rich B2 phase) and corresponding binary and ternary phase diagrams. The composition of the $\sigma$ particles can be described as ( $\mathrm{Ti}$, $\mathrm{Cr}, \mathrm{Nb}, \mathrm{V})_{0.7}(\mathrm{Ni}, \mathrm{Al})_{0.3}$. The total concentration of $\mathrm{Al}$ and $\mathrm{Ni}$ in the bcc and $\sigma$ phases remained almost constant in all the alloys; the fraction of the $\sigma$ particles can thus be predicted using the lever rule.

3) The $\sigma$ and $\mathrm{Ti}_{2} \mathrm{Ni}$ phases formation considerably influenced the mechanical properties of the alloys. For example, at room temperature the yield strength increased from $755 \mathrm{MPa}$ in the alloy with the single bcc phase structure $(x=0)$ to $1270 \mathrm{MPa}$ in the alloy with $32 \%$ of the second phases $(x=7)$. At the same time, ductility decreased from $>50 \%$ to $8.9 \%$, respectively. The alloy with the $\sigma$-phase matrix ( $\mathrm{x}=$ 10) fractured in the elastic region at room temperature. However, even the $\mathrm{x}=10$ alloy demonstrated the yield strength of only 285 $\mathrm{MPa}$ at $800^{\circ} \mathrm{C}$, while the other alloys were even softer.

\section{Data availability}

The raw/processed data required to reproduce these findings cannot be shared at this time as the data also forms part of an ongoing study.

\section{Declaration of competing interest}

The authors declare that they have no known competing financial interests or personal relationships that could have appeared to influence the work reported in this paper.

\section{CRediT authorship contribution statement}

E.S. Panina: Investigation, Data curation, Visualization. N.Yu Yurchenko: Investigation, Visualization, Writing - review \& editing. S. V. Zherebtsov: Writing - review \& editing, Validation. M.A. Tikhonovsky: Writing - review \& editing, Resources. M.V. Mishunin: Investigation. N.D. Stepanov: Conceptualization, Methodology, Supervision, Writing - original draft.

\section{Acknowledgments}

The authors gratefully acknowledge the financial support from the Russian Science Foundation Grant № 19-79-30066. The authors are grateful to the personnel of the Joint Research Center, «Technology and Materials», Belgorod State National Research University, for their assistance with the instrumental analysis.

\section{Appendix A. Supplementary data}

Supplementary data to this article can be found online at https://doi. org/10.1016/j.msea.2020.139409. 


\section{References}

[1] O.N. Senkov, G.B. Wilks, D.B. Miracle, C.P. Chuang, P.K. Liaw, Refractory highentropy alloys, Intermetallics 18 (2010) 1758-1765, https://doi.org/10.1016/j. intermet.2010.05.014.

[2] O.N. Senkov, D.B. Miracle, K.J. Chaput, J.-P. Couzinie, Development and exploration of refractory high entropy alloys-a review, J. Mater. Res. 33 (2018) 3092-3128, https://doi.org/10.1557/jmr.2018.153.

[3] J.H. Perepezko, Materials science. The hotter the engine, the better, Science 326 (2009) 1068-1069, https://doi.org/10.1126/science.1179327.

[4] D.B. Miracle, O.N. Senkov, A critical review of high entropy alloys and related concepts, Acta Mater. 122 (2017) 448-511, https://doi.org/10.1016/j. actamat.2016.08.081.

[5] O.N. Senkov, G.B. Wilks, J.M. Scott, D.B. Miracle, Mechanical properties of Nb 25Mo 25Ta 25W 25 and V 20Nb 20Mo 20Ta 20W 20 refractory high entropy alloys, Intermetallics 19 (2011) 698-706, https://doi.org/10.1016/j. intermet.2011.01.004.

[6] B. Gorr, F. Müller, M. Azim, H.-J. Christ, T. Müller, H. Chen, A. Kauffmann, M. Heilmaier, High-temperature oxidation behavior of refractory high-entropy alloys: effect of alloy composition, Oxid. Metals 88 (2017), https://doi.org/ 10.1007/s11085-016-9696-y.

[7] S. Gorsse, D.B. Miracle, O.N. Senkov, Mapping the world of complex concentrated alloys, Acta Mater. 135 (2017) 177-187, https://doi.org/10.1016/j. actamat.2017.06.027.

[8] T.M. Butler, K.J. Chaput, Native oxidation resistance of Al20Nb30Ta10Ti30Zr10 refractory complex concentrated alloy (RCCA), J. Alloys Compd. 787 (2019) 606-617, https://doi.org/10.1016/J.JALLCOM.2019.02.128.

[9] B. Kang, J. Lee, H.J. Ryu, S.H. Hong, Ultra-high strength WNbMoTaV high-entropy alloys with fine grain structure fabricated by powder metallurgical process, Mater. Sci. Eng. 712 (2018) 616-624, https://doi.org/10.1016/J.MSEA.2017.12.021.

[10] B. Kang, T. Kong, A. Raza, H.J. Ryu, S.H. Hong, Fabrication, microstructure and mechanical property of a novel Nb-rich refractory high-entropy alloy strengthened by in-situ formation of dispersoids, Int. J. Refract. Metals Hard Mater. (2019), https://doi.org/10.1016/J.IJRMHM.2019.02.009.

[11] O.N. Senkov, S.V. Senkova, C.F. Woodward, Effect of aluminum on the microstructure and properties of two refractory high-entropy alloys, Acta Mater. 68 (2014) 214-228, https://doi.org/10.1016/j.actamat.2014.01.029.

[12] O.N. Senkov, C. Woodward, D.B. Miracle, Microstructure and properties of aluminum-containing refractory high-entropy alloys, JOM 66 (2014) 2030-2042, https://doi.org/10.1007/s11837-014-1066-0.

[13] O.N. Senkov, S.V. Senkova, C. Woodward, D.B. Miracle, Low-density, refractory multi-principal element alloys of the Cr-Nb-Ti-V-Zr system: microstructure and phase analysis, Acta Mater. 61 (2013) 1545-1557, https://doi.org/10.1016/j. actamat.2012.11.032.

[14] O.N. Senkov, S. V Senkova, D.B. Miracle, C. Woodward, Mechanical properties of low-density, refractory multi-principal element alloys of the $\mathrm{Cr}-\mathrm{Nb}-\mathrm{Ti}-\mathrm{V}-\mathrm{Zr}$ system, Mater. Sci. Eng. 565 (2013) 51-62, https://doi.org/10.1016/j. msea.2012.12.018.

[15] N.Y. Yurchenko, N.D. Stepanov, D.G. Shaysultanov, M.A. Tikhonovsky, G. A. Salishchev, Effect of Al content on structure and mechanical properties of the AlxCrNbTiVZr (x = 0;0.25; 0.5; 1) high-entropy alloys, Mater. Char. 121 (2016) 125-134, https://doi.org/10.1016/j.matchar.2016.09.039.

[16] N.D. Stepanov, N.Y. Yurchenko, D.V. Skibin, M.A. Tikhonovsky, G.A. Salishchev, Structure and mechanical properties of the $\mathrm{AlCr}_{\mathrm{x}} \mathrm{NbTiV}(\mathrm{x}=0,0.5,1,1.5)$ high entropy alloys, J. Alloys Compd. 652 (2015) 266-280, https://doi.org/10.1016/j. jallcom.2015.08.224.

[17] B. Gorr, M. Azim, H.J. Christ, T. Mueller, D. Schliephake, M. Heilmaier, Phase equilibria, microstructure, and high temperature oxidation resistance of novel refractory high-entropy alloys, J. Alloys Compd. 624 (2015), https://doi.org/ 10.1016/j.jallcom.2014.11.012.

[18] F. Müller, B. Gorr, H.-J. Christ, J. Müller, B. Butz, H. Chen, A. Kauffmann, M. Heilmaier, On the oxidation mechanism of refractory high entropy alloys, Corrosion Sci. (2019) 108161, https://doi.org/10.1016/J.CORSCI.2019.108161.

[19] N.Y. Yurchenko, N.D. Stepanov, S.V. Zherebtsov, M.A. Tikhonovsky, G. A. Salishchev, Structure and mechanical properties of B2 ordered refractory AlNbTiVZrx (x = 0-1.5) high-entropy alloys, Mater. Sci. Eng. 704 (2017) 82-90, https://doi.org/10.1016/j.msea.2017.08.019.

[20] H. Chen, A. Kauffmann, S. Seils, T. Boll, C.H. Liebscher, I. Harding, K.S. Kumar, D. V. Szabó, S. Schlabach, S. Kauffmann-Weiss, F. Müller, B. Gorr, H.-J. Christ, M. Heilmaier, Crystallographic ordering in a series of Al-containing refractory high entropy alloys Ta-Nb-Mo-Cr-Ti-Al, Acta Mater. (2019), https://doi.org/10.1016/J. ACTAMAT.2019.07.001.

[21] J.K. Jensen, B.A. Welk, R.E.A. Williams, J.M. Sosa, D.E. Huber, O.N. Senkov, G. B. Viswanathan, H.L. Fraser, Characterization of the microstructure of the compositionally complex alloy Al1Mo0.5Nb1Ta0.5Ti1Zr1, Scripta Mater. 121 (2016) 1-4, https://doi.org/10.1016/j.scriptamat.2016.04.017.

[22] O.N. Senkov, D. Isheim, D.N. Seidman, A.L. Pilchak, Development of a refractory high entropy superalloy, Entropy 18 (2016), https://doi.org/10.3390/e18030102.

[23] W. Chen, Q.H. Tang, H. Wang, Y.C. Xie, X.H. Yan, P.Q. Dai, Microstructure and mechanical properties of a novel refractory AlNbTiZr high-entropy alloy, Mater. Sci. Technol. (2018) 1-7, https://doi.org/10.1080/02670836.2018.1446267.

[24] O.N. Senkov, J.K. Jensen, A.L. Pilchak, D.B. Miracle, H.L. Fraser, Compositional variation effects on the microstructure and properties of a refractory high-entropy superalloy AlMo0.5NbTa0.5TiZr, Mater. Des. 139 (2018) 498-511, https://doi. org/10.1016/j.matdes.2017.11.033.
[25] N.Y. Yurchenko, N.D. Stepanov, A.O. Gridneva, M.V. Mishunin, G.A. Salishchev, S. $\mathrm{V}$. Zherebtsov, Effect of $\mathrm{Cr}$ and $\mathrm{Zr}$ on phase stability of refractory Al-Cr-Nb-Ti-V-Zr high-entropy alloys, J. Alloys Compd. (2018), https://doi.org/10.1016/j. jallcom.2018.05.099.

[26] N.D. Stepanov, N.Y. Yurchenko, A.O. Gridneva, S.V. Zherebtsov, Y.V. Ivanisenko, G.A. Salishchev, Structure and hardness of B2 ordered refractory AlNbTiVZr0.5 high entropy alloy after high-pressure torsion, Mater. Sci. Eng. 716 (2018) 308-315, https://doi.org/10.1016/J.MSEA.2018.01.061.

[27] V. Soni, O.N. Senkov, B. Gwalani, D.B. Miracle, R. Banerjee, Microstructural design for improving ductility of an initially brittle refractory high entropy alloy, Sci. Rep. 8 (2018) 8816, https://doi.org/10.1038/s41598-018-27144-3.

[28] J.Y. He, H. Wang, H.L. Huang, X.D. Xu, M.W. Chen, Y. Wu, X.J. Liu, T.G. Nieh, K. An, Z.P. Lu, A precipitation-hardened high-entropy alloy with outstanding tensile properties, Acta Mater. 102 (2016) 187-196, https://doi.org/10.1016/j. actamat.2015.08.076.

[29] W.H. Liu, Z.P. Lu, J.Y. He, J.H. Luan, Z.J. Wang, B. Liu, Y. Liu, M.W. Chen, C.T. Liu, Ductile CoCrFeNiMox high entropy alloys strengthened by hard intermetallic phases, Acta Mater. 116 (2016), https://doi.org/10.1016/j.actamat.2016.06.063.

[30] L. Zhang, D. Zhou, B. Li, Anomalous microstructure and excellent mechanical properties of Ni $35 \mathrm{Al} 21.67 \mathrm{Cr} 21.67 \mathrm{Fe} 21.67$ high-entropy alloy with BCC and B2 structure, Mater. Lett. 216 (2018) 252-255, https://doi.org/10.1016/j. matlet.2018.01.124.

[31] J.Y. He, H. Wang, Y. Wu, X.J. Liu, H.H. Mao, T.G. Nieh, Z.P. Lu, Precipitation behavior and its effects on tensile properties of FeCoNiCr high-entropy alloys, Intermetallics 79 (2016) 41-52, https://doi.org/10.1016/j.intermet.2016.09.005.

[32] N.D. Stepanov, N.Y. Yurchenko, M.A. Tikhonovsky, G.A. Salishchev, Effect of carbon content and annealing on structure and hardness of the CoCrFeNiMn-based high entropy alloys, J. Alloys Compd. 687 (2016) 59-71, https://doi.org/10.1016/ j.jallcom.2016.06.103.

[33] N.D. Stepanov, D.G. Shaysultanov, R.S. Chernichenko, M.A. Tikhonovsky, S $\mathrm{V}$. Zherebtsov, Effect of $\mathrm{Al}$ on structure and mechanical properties of $\mathrm{Fe}-\mathrm{Mn}$-Cr-Ni$\mathrm{Al}$ non-equiatomic high entropy alloys with high Fe content, J. Alloys Compd. 770 (2018) 194-203, https://doi.org/10.1016/j.jallcom.2018.08.093.

[34] B. Gwalani, S. Gorsse, D. Choudhuri, M. Styles, Y. Zheng, R.S. Mishra, R. Banerjee, Modifying transformation pathways in high entropy alloys or complex concentrated alloys via thermo-mechanical processing, Acta Mater. 153 (2018) 169-185, https://doi.org/10.1016/J.ACTAMAT.2018.05.009.

[35] W.H. Liu, T. Yang, C.T. Liu, Precipitation hardening in CoCrFeNi-based high entropy alloys, Mater. Chem. Phys. (2017), https://doi.org/10.1016/j matchemphys.2017.07.037.

[36] N.D. Stepanov, D.G. Shaysultanov, G.A. Salishchev, M.A. Tikhonovsky, E. E. Oleynik, A.S. Tortika, O.N. Senkov, Effect of $v$ content on microstructure and mechanical properties of the $\mathrm{CoCrFeMnNiV}_{\mathrm{x}}$ high entropy alloys, J. Alloys Compd. 628 (2015), https://doi.org/10.1016/j.jallcom.2014.12.157.

[37] Y. Tong, D. Chen, B. Han, J. Wang, R. Feng, T. Yang, C. Zhao, Y.L. Zhao, W. Guo, Y. Shimizu, C.T. Liu, P.K. Liaw, K. Inoue, Y. Nagai, A. Hu, J.J. Kai, Outstanding tensile properties of a precipitation-strengthened FeCoNiCrTi0.2 high-entropy alloy at room and cryogenic temperatures, Acta Mater. 165 (2019) 228-240, https://doi.org/10.1016/J.ACTAMAT.2018.11.049.

[38] Y. Zhou, X. Jin, L. Zhang, X. Du, B. Li, A hierarchical nanostructured Fe $34 \mathrm{Cr} 34 \mathrm{Ni}$ $14 \mathrm{Al} 14$ Co 4 high-entropy alloy with good compressive mechanical properties, Mater. Sci. Eng., A (2018), https://doi.org/10.1016/j.msea.2018.01.034.

[39] N.D. Stepanov, N.Y. Yurchenko, E.S. Panina, M.A. Tikhonovsky, S.V. Zherebtsov, Precipitation-strengthened refractory Al0. 5CrNbTi2V0.5 High Entropy Alloy, Elsevier, 2017, https://doi.org/10.1016/j.matlet.2016.11.030.

[40] N.Y. Yurchenko, E.E.S. Panina, S.V.S. Zherebtsov, M.M.A. Tikhonovsky, G.A. G. Salishchev, N.D.N. Stepanov, Microstructure evolution of a novel low-density Ti$\mathrm{Cr}-\mathrm{Nb}-\mathrm{V}$ refractory high entropy alloy during cold rolling and subsequent annealing, Mater. Char. (2019) 109980, https://doi.org/10.1016/j. matchar.2019.109980.

[41] M.C. Troparevsky, J.R. Morris, P.R.C. Kent, A.R. Lupini, G.M. Stocks, Criteria for predicting the formation of single-phase high-entropy alloys, Phys. Rev. X. 5 (2015), https://doi.org/10.1103/PhysRevX.5.011041.

[42] W.C. Oliver, G.M. Pharr, Measurement of hardness and elastic modulus by instrumented indentation: advances in understanding and refinements to methodology, J. Mater. Res. 19 (2004) 3-20, https://doi.org/10.1557/ jmr.2004.19.1.3.

[43] O.N. Senkov, S. Rao, K.J. Chaput, C. Woodward, Compositional effect on microstructure and properties of NbTiZr-based complex concentrated alloys, Acta Mater. 151 (2018) 201-215, https://doi.org/10.1016/j.actamat.2018.03.065.

[44] N.D. Stepanov, N. Yu Yurchenko, D.G. Shaysultanov, G.A. Salishchev, M. A. Tikhonovsky, Effect of $\mathrm{Al}$ on structure and mechanical properties of AlxNbTiVZr $(\mathrm{x}=0,0.5,1,1.5)$ high entropy alloys, Mater. Sci. Technol. (United Kingdom). 31 (2015) 1184-1193, https://doi.org/10.1179/1743284715Y.0000000032.

[45] D. Schliephake, A.E. Medvedev, M.K. Imran, S. Obert, D. Fabijanic, M. Heilmaier, A. Molotnikov, X. Wu, Precipitation behaviour and mechanical properties of a novel Al0.5MoTaTi complex concentrated alloy, Scripta Mater. 173 (2019) 16-20, https://doi.org/10.1016/j.scriptamat.2019.07.033.

[46] O.N.N. Senkov, J.D.D. Miller, D.B.B. Miracle, C. Woodward, Accelerated Exploration of Multi-Principal Element Alloys for Structural Applications, vol. 50, 2015, pp. 32-48, https://doi.org/10.1016/j.calphad.2015.04.009.

[47] K.N. Wertz, J.D. Miller, O.N. Senkov, Toward multi-principal component alloy discovery: assessment of CALPHAD thermodynamic databases for prediction of novel ternary alloy systems, J. Mater. Res. (2018) 1-14, https://doi.org/10.1557/ jmr.2018.61. 
[48] (n.d No Title, accessed, https://www.thermocalc.com/media/54070/tchea 3_extended_info.pdf. (Accessed 6 November 2019).

[49] S. Gorsse, O.N. Senkov, About the reliability of CALPHAD predictions in multicomponent systems, Entropy 20 (2018), https://doi.org/10.3390/ e20120899.

[50] SpringerMaterials - properties of materials, (n.d.), accessed, https://materials.spri nger.com/. (Accessed 6 November 2019).

[51] V. Raghavan, Al-Ni-Ti (Aluminum-Nickel-Titanium), J. Phase Equilibria Diffus. 26 (2005) 268-272, https://doi.org/10.1007/s11669-005-0116-2.

[52] N. Yukawa, M. Hida, T. Imura, Y. Mizuno, M. Kawamura, Structure of chromiumrich $\mathrm{Cr}-\mathrm{Ni}$, Cr-Fe, Cr-Co, and Cr-Ni-Fe alloy particles made by evaporation in argon, Metall. Trans. 3 (1972) 887-895, https://doi.org/10.1007/BF02647663.

[53] P. Nash, The Cr-Ni (Chromium-Nickel) system, Bull. Alloy Phase Diagrams 7 (1986) 466-476, https://doi.org/10.1007/BF02867812.

[54] D.G. Shaysultanov, N.D. Stepanov, G.A. Salishchev, M.A. Tikhonovsky, Effect of heat treatment on the structure and hardness of high-entropy alloys CoCrFeNiMnV $x(x=0.25,0.5,0.75,1)$, Phys. Met. Metallogr. 118 (2017) 579-590, https://doi. org/10.1134/S0031918X17060084.

[55] D.B. Miracle, High-entropy alloys: a current evaluation of founding ideas and core effects and exploring "nonlinear alloys, JOM. 69 (2017) 2130-2136, https://doi. org/10.1007/s11837-017-2527-z.

[56] M.H. Tsai, R.C. Tsai, T. Chang, W.F. Huang, Intermetallic Phases in High-Entropy Alloys: Statistical Analysis of Their Prevalence and Structural Inheritance, Metals (Basel) vol. 9 (2019), https://doi.org/10.3390/met9020247.

[57] E.O. Hall, S.H. Algie, The sigma phase, Metall. Rev. 11 (1966) 61-88, https://doi org/10.1179/mtlr.1966.11.1.61.
[58] C.-C. Hsieh, W. Wu, Overview of intermetallic sigma ( $\sigma)$ phase precipitation in stainless steels, ISRN Metall 2012 (2012) 1-16, https://doi.org/10.5402/2012/ 732471.

[59] N.D. Stepanov, D.G. Shaysultanov, G.A. Salishchev, M.A. Tikhonovsky, E. E. Oleynik, A.S. Tortika, O.N. Senkov, Effect of V content on microstructure and mechanical properties of the CoCrFeMnNiVx high entropy alloys, J. Alloys Compd. 628 (2015) 170-185, https://doi.org/10.1016/j.jallcom.2014.12.157.

[60] G.A. Salishchev, M.A. Tikhonovsky, D.G. Shaysultanov, N.D. Stepanov, A. V. Kuznetsov, I.V. Kolodiy, A.S. Tortika, O.N. Senkov, Effect of Mn and v on structure and mechanical properties of high-entropy alloys based on CoCrFeNi system, J. Alloys Compd. 591 (2014) 11-21, https://doi.org/10.1016/j. jallcom.2013.12.210.

[61] N.D. Stepanov, D.G. Shaysultanov, M.A. Tikhonovsky, G.A. Salishchev, Tensile properties of the $\mathrm{Cr}$-Fe-Ni-Mn non-equiatomic multicomponent alloys with different Cr contents, Mater. Des. 87 (2015) 60-65, https://doi.org/10.1016/j. matdes.2015.08.007.

[62] Y.H. Jo, W.M. Choi, D.G. Kim, A. Zargaran, K. Lee, H. Sung, S.S. Sohn, H.S. Kim, B. J. Lee, S. Lee, Utilization of brittle $\sigma$ phase for strengthening and strain hardening in ductile VCrFeNi high-entropy alloy, Mater. Sci. Eng. 743 (2019) 665-674, https://doi.org/10.1016/j.msea.2018.11.136.

[63] M.V. Klimova, D.G. Shaysultanov, S.V. Zherebtsov, N.D. Stepanov, Effect of second phase particles on mechanical properties and grain growth in a CoCrFeMnNi high entropy alloy, Mater. Sci. Eng. 748 (2019) 228-235, https://doi.org/10.1016/J. MSEA.2019.01.112.

[64] J.W. Bae, J. Moon, M.J. Jang, D. Yim, D. Kim, S. Lee, H.S. Kim, Trade-off between tensile property and formability by partial recrystallization of $\mathrm{CrMnFeCoNi}$ highentropy alloy, Mater. Sci. Eng. 703 (2017) 324-330, https://doi.org/10.1016/J. MSEA.2017.07.079. 